\title{
Transition Metal Chemistry
}

\section{Modifying the structure and the magnetic properties of fumarato bridging $\mathrm{Mn}$ coordination polymers through different dimethyl-2,2'-bipyridine co-ligand \\ --Manuscript Draft--}

\begin{tabular}{|c|c|}
\hline Manuscript Number: & \\
\hline Full Title: & $\begin{array}{l}\text { Modifying the structure and the magnetic properties of fumarato bridging } \mathrm{Mn} \\
\text { coordination polymers through different dimethyl-2,2'-bipyridine co-ligand }\end{array}$ \\
\hline Article Type: & Research Article \\
\hline Keywords: & $\begin{array}{l}\text { Mn coordination polymers; Fumarato; Dialkyl-2,2'-Bipyridine; Supramolecular } \\
\text { network; Magnetic properties }\end{array}$ \\
\hline Corresponding Author: & $\begin{array}{l}\text { Victor Sanchez-Mendieta } \\
\text { Universidad Autónoma del Estado de México Facultad de Quimica } \\
\text { Toluca, Mexico MEXICO }\end{array}$ \\
\hline $\begin{array}{l}\text { Corresponding Author Secondary } \\
\text { Information: }\end{array}$ & \\
\hline Corresponding Author's Institution: & Universidad Autónoma del Estado de México Facultad de Quimica \\
\hline $\begin{array}{l}\text { Corresponding Author's Secondary } \\
\text { Institution: }\end{array}$ & \\
\hline First Author: & Antonio Tellez-Lopez \\
\hline First Author Secondary Information: & \\
\hline Order of Authors: & Antonio Tellez-Lopez \\
\hline & Victor Sanchez-Mendieta \\
\hline & Jonathan Jaramillo-Garcia \\
\hline & Luis D Rosales-Vazquez \\
\hline & Ivan Garcia-Orozco \\
\hline & Raul A Morales-Luckie \\
\hline & Roberto Escudero \\
\hline & Francisco Morales-Leal \\
\hline Order of Authors Secondary Informe & \\
\hline Funding Information: & $\begin{array}{l}\text { Universidad Autónoma del Estado de } \quad \text { Dr. Victor Sanchez-Mendieta } \\
\text { México }\end{array}$ \\
\hline Abstract: & $\begin{array}{l}\text { Novel manganese coordination polymers }\{\mathrm{Mn}(\mathrm{fum})(\mathrm{dmmb})(\mathrm{H} 2 \mathrm{O}) 2\} \mathrm{n}(1) \text { and } \\
\{[\mathrm{Mn} 2(\mathrm{fum}) 2(4 \mathrm{dmb}) 2] \cdot \mathrm{H} 2 \mathrm{O}\} \mathrm{n}(2) ; \text { (fum }=\text { fumarato; } 5 \mathrm{dmb}=5,5^{\prime}-\text {-dimethyl-2,2'-bipyridine; } \\
4 \mathrm{dmb}=4,4^{\prime} \text {-dimethyl-2,2'-bipyridine) were obtained by self-assembly, one-pot, solution } \\
\text { reactions at ambient conditions. Fum ligand acquires different coordination modes } \\
\text { under different dmb ancillary ligand, which promotes different crystal structure } \\
\text { formation, including divergent dimensionality. X-ray single crystal data reveal that } 1 \\
\text { crystallizes in a monoclinic system with C2/c space group and forms an infinite one- } \\
\text { dimensional (1D) polymer. Mn(II) ion is six-coordinated and displays a distorted } \\
\text { octahedral configuration. In addition, the solid-state self-assembly of the polymeric } \\
\text { structure of } 1 \text { give rise to a } 2 \mathrm{D} \text { supramolecular framework, mainly throughout hydrogen } \\
\text { bonding. Whereas, } 2 \text { crystallizes in a monoclinic system with a Cc space group and } \\
\text { forms an infinite two-dimensional (2D) coordination polymer having dinuclear units. } \\
\text { Mn(II) ion displays a distorted octahedral configuration. Thermal stability of the } \\
\text { polymers was also determined. Accordingly to variable-temperature magnetic } \\
\text { measurements, } 1 \text { is paramagnetic and } 2 \text { exhibits weak antiferromagnetic coupling } \\
\text { between adjacent Mn(II) ions. }\end{array}$ \\
\hline
\end{tabular}


Click here to view linked References
1

\section{Modifying the structure and the magnetic properties of fumarato bridging Mn coordination polymers through different dimethyl-2,2'-bipyridine co-ligand}

Antonio Téllez-López, ${ }^{1}$ Víctor Sánchez-Mendieta, ${ }^{1 *}$ Jonathan Jaramillo-García, ${ }^{1}$ Luis D.

Rosales-Vázquez, ${ }^{1}$ Iván García-Orozco ${ }^{2}$, Raúl A. Morales-Luckie, ${ }^{2}$ Roberto Escudero ${ }^{3 *}$ and Francisco Morales-Leal ${ }^{3}$

${ }^{1}$ Facultad de Química, Universidad Autónoma del Estado de México. Paseo Colón y Paseo Tollocan. Toluca, Estado de México. 50120. México.

${ }^{2}$ Centro Conjunto de Investigación en Química Sustentable UAEM-UNAM, Carretera Toluca-Ixtlahuaca Km. 14.5, Tlachaloya, Toluca, Estado de México. México.

${ }^{3}$ Instituto de Investigaciones en Materiales, Universidad Nacional Autónoma de México. Apartado Postal 70-360, México, Distrito Federal, 04510, México.

*Authors to whom correspondence should be addressed: vsanchezm@uaemex.mx (V. Sánchez-Mendieta); escu@unam.mx (R. Escudero).

\begin{abstract}
Novel manganese coordination polymers $\left\{\mathrm{Mn}(\mathrm{fum})(5 \mathrm{dmb})\left(\mathrm{H}_{2} \mathrm{O}\right)_{2}\right\}_{\mathrm{n}} \quad$ (1) and $\left\{\left[\mathrm{Mn}_{2}(\text { fum })_{2}(4 \mathrm{dmb})_{2}\right] \cdot \mathrm{H}_{2} \mathrm{O}\right\}_{\mathrm{n}}(2) ;\left(\right.$ fum = fumarato; $5 \mathrm{dmb}=5,5^{\prime}$ '-dimethyl-2,2'-bipyridine;
\end{abstract}


$4 \mathrm{dmb}=4,4^{\prime}$-dimethyl-2,2'-bipyridine) were obtained by self-assembly, one-pot, solution reactions at ambient conditions. Fum ligand acquires different coordination modes under different dmb ancillary ligand, which promotes different crystal structure formation, including divergent dimensionality. X-ray single crystal data reveal that $\mathbf{1}$ crystallizes in a monoclinic system with $\mathrm{C} 2 / \mathrm{c}$ space group and forms an infinite one-dimensional (1D) polymer. $\mathrm{Mn}(\mathrm{II})$ ion is six-coordinated and displays a distorted octahedral configuration. In addition, the solid-state self-assembly of the polymeric structure of $\mathbf{1}$ give rise to a $2 \mathrm{D}$ supramolecular framework, mainly throughout hydrogen bonding. Whereas, 2 crystallizes in a monoclinic system with a Cc space group and forms an infinite two-dimensional (2D) coordination polymer having dinuclear units. Mn(II) ion displays a distorted octahedral configuration. Thermal stability of the polymers was also determined. Accordingly to variable-temperature magnetic measurements, $\mathbf{1}$ is paramagnetic and $\mathbf{2}$ exhibits weak antiferromagnetic coupling between adjacent $\mathrm{Mn}$ (II) ions.

Keywords: Mn coordination polymers; Fumarato; Dialkyl-2,2'-Bipyridine; Supramolecular network; Magnetic properties.

\section{Introduction}

Research on the fundamentals of novel coordination polymers continues being relevant due to the synergic relationship between structural and physicochemical characteristics with 
properties; in particular, the search of tailor-made methodologies to suit desired properties and further applications of these materials, has long been pursued [1]. Several strategies have been developed to synthesize bivalent-transition metal mixed ligands coordination polymers containing nitrogen and oxygen donor ligands [2]. Self-assembly of small molecules, compounds or complexes, has demonstrated to be an appreciated process for synthesizing large structures with a minimum effort. However, the self-assembly process is sometimes accompanied by an uncertainty halo, due to unpredictable interactions among metal centers and ligands, especially when weak forces (i.e. hydrogen bonding, $\pi-\pi$ interactions) and/or solvents, such as water, are involved [3]. Moreover, crystal engineering refers to the construction of crystal structures from organic and metal-organic compounds using design principles that come from an understanding of the intermolecular interactions in the molecular solids [4]. Also, supramolecular frameworks based on metal ions and organic ligands have gained interest recently due to their fascinating structural diversity and their potential applications in catalysis, sensors, porosity and non-linear optics [5]. Among the most used bridging ligands for transition metal ions are the dicarboxylate ligands [6]. In particular, fum ligand has been extensively used for the formation of complexes [7] and coordination polymers [8]. We selected this ion-bridging ligand due to its simple chemical structure and its dual chemical functionality, which allow generating complexes or polymers, depending on its coordination modes. The use of 2,2'-bipyridine as ancillary ligand had become relevant in our previous studies on complexes [9] and coordination polymers [10] of transition metals. There are previous reports mainly on structural studies of coordination polymers formed by the reaction of a $\mathrm{Mn}(\mathrm{II})$ salt with fum as bridging ligand and 2,2'bipyridine [11], and the related 1,10-phenantroline [12], as co-ligands. Magnetism studies were not reported for those compounds. Thus, we decided to keep using one of the most 
studied nitrogen donor ligand [13], and just varying the alkyl-substituent on it, in order to verify the influence of the co-ligand steric hindrance on the dimensionality and crystalline structure of coordination polymers. So far, very few articles have been published about the use of different di-alkyl-2,2'-bipyridines as ancillary ligands, either in transition metal complexes [14] or coordination polymers $[15,16]$, and none of them concerning their steric hindrance influencing structural characteristics and therefore properties.

Herein, we describe the easy synthesis, crystalline molecular and supramolecular structures details, thermal analyses and magnetic properties of novel coordination polymers of $\mathrm{Mn}$ (II), $\mathbf{1}$ and $\mathbf{2}$, bearing fum as bridging ligand and two different dimethyl-2,2'-bipyridine as ancillary ligands.

\section{Experimental}

All chemicals were of analytical grade, purchased commercially (Aldrich) and were used without further purification. All syntheses were carried out in aerobic and ambient conditions. Elemental analyses for $\mathrm{C}, \mathrm{H}, \mathrm{N}$ were carried out for standard methods using a Vario Micro-Cube analyzer. IR spectra of the complexes were determined as $\mathrm{KBr}$ disks in an Avatar 360 FT-IR Nicolet spectrophotometer from $4000-400 \mathrm{~cm}^{-1}$. Thermogravimetric analyses were performed in a TA Instruments equipment, under $\mathrm{N}_{2}$ atmosphere, at a heating rate of $10{ }^{\circ} \mathrm{C} \min ^{-1}$, from 20 to $800{ }^{\circ} \mathrm{C}$. Magnetic characteristics of $\mathbf{1}$ and $\mathbf{2}$ were determined in a MPMS Quantum Design magnetometer with measurements performed at zero field cooling (ZFC) and field cooling (FC) from 2-300 K and decreasing. The applied magnetic 
field was $100 \mathrm{Oe}$, and the total diamagnetic corrections were estimated using Pascal's constants as $-250 \times 10^{-6} \mathrm{~cm}^{3} \mathrm{~mol}^{-1}$.

\section{Synthesis of $\left\{\mathrm{Mn}(\mathrm{fum})(5 \mathrm{dmb})\left(\mathrm{H}_{2} \mathrm{O}\right)_{2}\right\}_{\mathrm{n}}(1)$}

A methanol solution $(60 \mathrm{ml})$ of 5,5'-dimethyl-2,2'-bipyridine $(0.0921 \mathrm{~g}$; $0.5 \mathrm{mmol})$ was added to an aqueous solution $(30 \mathrm{ml})$ of sodium fumarate $(0.0800 \mathrm{~g} ; 0.5 \mathrm{mmol})$ while stirring. To this solution, $\mathrm{MnCl}_{2} \cdot 4 \mathrm{H}_{2} \mathrm{O}(0.0989 \mathrm{~g} ; 0.5 \mathrm{mmol})$ in $30 \mathrm{ml}$ of de-ionized water was added. A translucent yellow colored solution was obtained. After four days, small yellow crystals were obtained then filtered and washed with a 50:50 deionized water-methanol mixture and air-dried. Yield: $76 \%$ based on metal precursor. Anal. calc. for $\mathrm{C}_{16} \mathrm{H}_{18} \mathrm{MnN}_{2} \mathrm{O}_{6}$ ( $F W=389.16): C, 49.35 ; \mathrm{H}, 4.62 ; \mathrm{N}, 7.19 \%$. Found: $\mathrm{C}, 48.91 ; \mathrm{H}, 4.60 ; \mathrm{N}, 7.09 \%$. IR $\left(\mathrm{cm}^{-1}\right)$ : 3225 (vs, br), 2910 (s), 1960 (w), 1900 (w), 1830 (w), 1701 (w), 1545 (s), 1480 (s, sh), 1365 (s), 1242 (m), 1200 (m), 1160 (m), 1040 (m), 1003 (w), 730 (w), 675 (s, sh), 580 (s, sh), 470 (m), $413(\mathrm{~m})$.

\section{Synthesis of $\left\{\left[\mathrm{Mn}_{2}(\mathrm{fum})_{2}(4 \mathrm{dmb})_{2}\right] \cdot \mathrm{H}_{2} \mathrm{O}\right\}_{\mathrm{n}}(2)$}

A methanol solution $(5 \mathrm{ml})$ of fumaric acid $(0.0348 \mathrm{~g} ; 0.3 \mathrm{mmol})$ was added to an aqueous solution ( $5 \mathrm{ml}$ ) of sodium hydroxide $(0.0240 \mathrm{~g} ; 0.6 \mathrm{mmol})$, while stirring. Then, $\mathrm{MnCl}_{2} \cdot 4 \mathrm{H}_{2} \mathrm{O}$ $(0.0593 \mathrm{~g} ; 0.3 \mathrm{mmol})$ dissolved in $5 \mathrm{ml}$ of deionized water was added to the previous solution, under constant stirring. Finally, a methanol solution (5 ml) of 4,4'-dimethyl-2,2'-bipyridine (0.0552 $\mathrm{g} ; 0.3 \mathrm{mmol})$ was added. A translucent yellow solution was obtained. After six days, yellow crystals were obtained then filtered, washed with a 50:50 deionized water-methanol mixture and air-dried. Yield: $42 \%$ based on metal precursor. Anal. calc. for $\mathrm{C}_{32} \mathrm{H}_{34} \mathrm{Mn}_{2} \mathrm{~N}_{4} \mathrm{O}_{11}$ $(\mathrm{FW}=760.51): \mathrm{C}, 50.54 ; \mathrm{H}, 4.51 ; \mathrm{N}, 7.37 \%$. Found: $\mathrm{C}, 52.86 ; \mathrm{H}, 4.29 ; \mathrm{N}, 7.68 \%$. IR (cm 
1): 3630 (s), 3500 (s, br), 3080 (m), 3060(s), 2960 (m), 2920 (m), 1960 (m), 1940 (m), 1880

(w), $1820(\mathrm{w}), 1600$ (vs), 1550 (vs), 1480 (s), 1390 (s), 1300 (m), 1240 (m), 1210 (m), 1130

(w), 1010 (s), 980 (m), 918 (s), 833 (s), 802 (s), 706 (m), 690 (vs, sh), 660 (s), 586 (s), 548

(m), $513(\mathrm{~m}), 424(\mathrm{w})$.

Crystal structure determination and refinement

Crystallographic data for $\mathbf{1}$ and $\mathbf{2}$ were collected on a Bruker SMART APEX DUO threecircle diffractometer equipped with an Apex II CCD detector using $\operatorname{MoK} \alpha(\lambda=0.71073 \AA$, Incoatec I $\mu \mathrm{S}$ microsource) at $100 \mathrm{~K}$ [17]. The crystals were coated with hydrocarbon oil, picked up with a nylon loop, and immediately mounted in the cold nitrogen stream $(100 \mathrm{~K})$ of the diffractometer. The structures were solved by direct methods (SHELXS-97) and refined by full-matrix least-squares on $\mathrm{F}^{2}$ [18] using the shelXle GUI [19]. The hydrogen atoms of the $\mathrm{C}-\mathrm{H}$ bonds were placed in idealized positions whereas the hydrogen atoms from $\mathrm{H}_{2} \mathrm{O}$ moieties were localized from the difference electron density map, and their position was refined with $\mathrm{U}_{\text {iso }}$ tied to the parent atom with distance restraints. The disordered hydrogens were refined using distance restraints (DFIX). The crystallographic data and refinement details for both polymers are summarized in table 1. Selected bond lengths and angles for 1 and $\mathbf{2}$ are listed in tables 2 and 3, respectively.

\section{Results and discussion}

\section{Synthesis and structures}

Using a very simple methodology of self-assembling solution reactions, equivalent amounts of sodium fumarate (fum), $\mathrm{MnCl}_{2} \cdot 4 \mathrm{H}_{2} \mathrm{O}, 5,5^{\prime}$-dimethyl-2,2'-bipyridine (5dmb) and 4,4'- 
dimethyl-2,2'-bipyridine (4dmb), respectively, were mixed in water-methanol solutions, under ambient conditions. Slow evaporation of solvents yielded light yellow crystals of $\mathbf{1}$ and 2. These crystals are insoluble in common solvents and appear to be air and moisture stable. $\left\{\mathrm{Mn}(\text { fum })(5 \mathrm{dmb})\left(\mathrm{H}_{2} \mathrm{O}\right)_{2}\right\}_{\mathrm{n}}(\mathbf{1})$ crystallizes in a monoclinic system with $\mathrm{C} 2 / \mathrm{c}$ space group and forms an infinite one-dimensional (1-D) coordination polymer (Fig. 1). The repeat molecular unit of 1 contains one $\mathrm{Mn}$ ion, one fum ligand, one $5 \mathrm{dmb}$ co-ligand and two coordinated water molecules. The coordination environment of the Mn ion is shown in Fig. 1a. The Mn ion is six-coordinated and surrounded by four oxygen atoms from two different fum ligands and the two water molecules, and two nitrogen atoms from one $5 \mathrm{dmb}$ ligand. The Mn ion displays a distorted octahedral configuration. The Mn-O bond lengths range from 2.161(5) to $2.1665(9) \AA$, while the Mn-N distance is $2.2818(10) \AA$, which are comparable values to those found on similar Mn(II) compounds [20, 21, 22]. In 1, the 1D zig-zag chain is formed due to the monodentate $\eta^{1}: \eta^{0}$ coordination mode of fum, and the trans configuration of its carboxylate groups, bridging thus the Mn ions (Fig. 1b). It is worthwhile to mention that the Mn $\cdots$ Mn distance in the $1 \mathrm{D}$ chain is $9.885 \AA$.

Intermolecular hydrogen-bonding interactions lead to the formation of a 2D supramolecular array in 1 (Fig. 2). These interactions are promoted by the presence of the aqua ligand and the non-coordinated oxygen atom of the fum carboxylate. This can be clearly observed in Fig. 2a, where the main $\mathrm{O}-\mathrm{H}---\mathrm{O}$ bindings are formed by the $\mathrm{O}-\mathrm{H}$ moiety $(\mathrm{O} 3)$ of the aqua ligand with each of the oxygen atom $(\mathrm{O} 2)$ of the non-coordinated side of one fum ligand. This is an intramolecular hydrogen bond. Furthermore, each coordinated water molecule generates a double hydrogen bridge, the one that is already described above, and another with one fum oxygen atom (O3) already coordinated to $\mathrm{Mn}(\mathrm{II})$ of a neighboring $1 \mathrm{D}$ polymeric 
chain (intermolecular hydrogen bonding) generating, thus, an extended 2D supramolecular

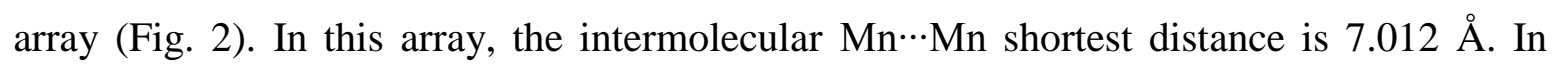
addition, in the crystalline lattice of $\mathbf{1}$ there are interchain $\pi-\pi$ stacking interactions from the pyridine rings of the $5 \mathrm{dmb}$ ligand, with distances of 3.999 and $4.860 \AA$.

$\left\{\left[\mathrm{Mn}_{2}(\mathrm{fum})_{2}(4 \mathrm{dmb})_{2}\right] \cdot \mathrm{H}_{2} \mathrm{O}\right\}_{\mathrm{n}}(2)$ crystallizes in a monoclinic system with a Cc space group and forms an infinite two-dimensional (2D) coordination polymer. The molecular structure of 2 consists of two crystallographic independent $\mathrm{Mn}^{2+}$ ions, two fum ligands, two $4 \mathrm{dmb}$ ligands and one guest $\mathrm{H}_{2} \mathrm{O}$ molecule (Fig. 3). Both $\mathrm{Mn}$ ions are six-coordinated and surrounded by four oxygen atoms from three different fum ligands and two nitrogen atoms from one $4 \mathrm{dmb}$ co-ligand. These $\mathrm{Mn}$ ions display a distorted octahedral configuration. The Mn-O bond lengths vary from 2.084(2) to 2.315(2) A, whilst the Mn-N distances range from 2.240(3) to 2.265(3) $\AA$, comparable values to those found on related Mn(II) complexes [16, 23, 24, 25]. In compound 1 the fum ligand assumes a $\mu_{4}$ coordination mode, in which two carboxylate groups show the $\mu_{2}-\eta^{1}: \eta^{1}$ bidentate mode. The carboxylate moieties of fum alternately bridge adjacent $\mathrm{Mn}$ (II) ions in a syn-syn configuration generating dinuclear units in a $1 \mathrm{D}$ chain motif. In these units the $\mathrm{Mn} \cdots \mathrm{Mn}$ shortest separation is $4.561 \AA$. These dinuclear units are further linked by another fum ligand in a bridging $\eta^{1}: \eta^{1}$ bidentate fashion, connecting, thus, the double-ion rows (Fig. 3). These two different coordination modes of fum ligand to the six-coordinated Mn ions, give rise to a unique 2D wrinkle-sheet array (Fig. 4). Also, in the crystalline lattice of 2 there are interlayer $\pi-\pi$ stacking interactions from the pyridine rings of $4 \mathrm{dmb}$ ligands, with distances ranging from 3.649 to $5.803 \AA$.

The three diverse coordination modes of fum: $\eta^{1}: \eta^{0}, \eta^{1}: \eta^{1}$ and $\mu_{2}-\eta^{1}: \eta^{1}$, occurring in polymers 1 and 2, respectively, seem to be promoted by the different dmb co-ligand present in each 
compound. This is, in $\mathbf{1}$ the $5 \mathrm{dmb}$ ancillary ligand may generate a steric hindrance around the Mn coordination sphere, which precludes the oxygen atoms from the fum ligand to coordinate further the Mn ions, directing thus to a 1D polymer and, due to the presence of a coordinated water molecule, into a stable 2D supramolecular structure. While, in 2 the $4 \mathrm{dmb}$ co-ligand possesses a less hindering structure, allowing the fum carboxylates to coordinate further with Mn before reaching its thermodynamically stable 2D crystal structure.

\section{Thermogravimetric analyses}

To examine the thermal stability of the crystalline polymers, thermal analyses were performed for 1 and 2 between 20 and $800^{\circ} \mathrm{C}$ (Fig. 5).

Polymers 1 and $\mathbf{2}$ exhibit mainly three decomposition stages. The first major weight loss $(10.00 \%)$ for 1 occurs between 120 and $160{ }^{\circ} \mathrm{C}$, the second one, with a weight loss of 46.05 $\%$ of the initial weight, takes place approximately between 258 and $325{ }^{\circ} \mathrm{C}$. The last weight loss $(20.34 \%)$ occurs around $390-430{ }^{\circ} \mathrm{C}$, from there only $18 \%$ of the initial sample weight remains at $800{ }^{\circ} \mathrm{C}$. Likewise, for 2 the first weight loss $(-2.60 \%)$ appears between 97 and $252{ }^{\circ} \mathrm{C}$, the second one, with a weight loss of $48.42 \%$, happens between 275 and $386{ }^{\circ} \mathrm{C}$, and the third loss $(-20 \%)$ occurs from 390 to $445{ }^{\circ} \mathrm{C}$, leaving around $27 \%$ of the initial sample weight at $800{ }^{\circ} \mathrm{C}$. In both complexes, the first decomposition stage can be endorsed to the loss of water; however, in $\mathbf{1}$ two coordinated water molecules are lost, whilst in $\mathbf{2}$ only one crystallization water molecule is lost. The rest of the stages can be attributed practically to the combined weight loss of the fum ligand (calcd. $29.30 \%$ for $\mathbf{1}$ and $31.49 \%$ for $\mathbf{2}$ ), and the 5dbpy (calcd. $47.33 \%$ ) and the $4 \mathrm{dmb}$ (calcd. 50.86\%) co-ligands, respectively. The residual of the initial weight loss, at $800{ }^{\circ} \mathrm{C}$, for both compounds can be assigned, roughly, to residual 
$\mathrm{MnO}$ (calcd. $18.22 \%$ for $\mathbf{1}$ and $19.58 \%$ for $\mathbf{2}$ ). It is evident that due to their different structural characteristics polymer $\mathbf{2}$ has a superior thermal robustness compared to $\mathbf{1}$ (Fig. 5).

\section{Magnetic properties}

DC magnetic susceptibility, $\chi$, was determined for $\mathbf{1}$ and $\mathbf{2}$, at zero field cooling (ZFC) and field cooling (FC) modes, from 2 - $300 \mathrm{~K}$ and decreasing, in an applied field of 1000 Oe. $\chi T$ values at room temperature are 4.14 and $8.85 \mathrm{~cm}^{3} \mathrm{~mol}^{-1} \mathrm{~K}$ for $\mathbf{1}$ and $\mathbf{2}$, respectively, which are close to the values expected for one $\left(4.37 \mathrm{~cm}^{3} \mathrm{~mol}^{-1} \mathrm{~K}\right)$ and two $\left(8.75 \mathrm{~cm}^{3} \mathrm{~mol}^{-1} \mathrm{~K}\right)$ magnetically isolated $\mathrm{Mn}^{2+}(S=5 / 2)$. However, as temperature is lowered, $\chi T$ value in $\mathbf{1}$ remains almost constant (Fig. 6), and only diminishes a bit at very low temperature, which means that this compound behaves as a paramagnetic system. However, in 2 , $\chi T$ value decreases first slowly and then rapidly, as temperature is lowered, until reaching a $\chi T$ value of $0.69 \mathrm{~cm}^{3} \mathrm{~mol}^{-1} \mathrm{~K}$ at $2 \mathrm{~K}$ (Fig. 6). This behavior implies that antiferromagnetic interactions can be occurring in $\mathbf{2}$. For $\mathbf{1}, \chi$ and $\chi^{-1}$ experimental values as a function of $T$ were fitted to Curie-Weiss law (Fig. 7), which confirmed that compound $\mathbf{1}$ only shows a paramagnetic behavior.

Because of the occurrence of dinuclear Mn(II) clusters along the 2D polymer structure in 2 (Fig. 3b), and due to the $\chi$ vs. $T$ plot analysis, where the susceptibility exhibits a maximum at $5.97 \mathrm{~K}\left(T_{N}\right)$ after which the $\chi$ value start to decrease, we believed that this compound would present antiferromagnetic interactions within the dimeric $\mathrm{Mn}(\mathrm{II})$ unit. Therefore, the experimental data were fit using Bleaney-Bowers equation (1) [26] for a coupled $S=5 / 2$ dimeric unit. 


$$
\chi=(1-\rho) \frac{N_{A} \mathrm{~g}^{2} \mu_{B}^{2}\left(2 e^{2 J / k_{B} T}\right)}{k_{B}(T-\theta)\left(1+3 e^{2 J / k_{B} T}\right)}+\rho \frac{N_{A} \mathrm{~g}^{2} \mu_{B}^{2}}{2 k_{B} T}
$$

where $\theta$ is the Curie-Weiss temperature and $J$ is the magnetic spin exchange interaction according to the Hamiltonian interaction: $H=-2 J\left(S_{1} \cdot S_{2}\right)$, between two $\mathrm{Mn}$ magnetic moments in the dimeric unit. The second term in equation (1) refers to the non-interacting paramagnetic species, with the factor $\rho$ as the molar fraction of these paramagnetic moments, $k_{B}$ is the Boltzmann constant, $N_{A}$ is the Avogadro number and $\mu_{\mathrm{B}}$ the Bohr magneton. The best fit of the experimental data was obtained with $J / k_{B}=-3.64 \mathrm{~K}, g=2.27, \theta=-12.8 \mathrm{~K}$ and $\rho=6.3 \%$ (Fig 8a). Thus, the Bleaney-Bowers equation describes very well the experimental results, confirming the antiferromagnetic interaction between two $\mathrm{Mn}(\mathrm{II})$. It is important to mention that this model has been applied for coordination polymers having similar dinuclear units as in compound 2 [27]. Fig. 8b shows the result of the fitting with Curie-Weiss law. The Curie-Weiss plots for 2 gave constants: $C=9.26 \mathrm{~cm}^{3} \mathrm{Kmol}^{-1}, \theta=-15.22 \mathrm{~K}$, validating, thus, the weak antiferromagnetic exchange occurring between $\mathrm{Mn}(\mathrm{II})$ ions in the dinuclear units of 2. Comparable $J$ values have been obtained for other similar weak antiferromagnetic systems [28]. So, the magnetic behavior of 2 agrees very well with a weak antiferromagnetic intramolecular interaction between $\mathrm{Mn}(\mathrm{II})$ ions, which has been usually found for the synsyn, equatorial-equatorial arrangement in carboxylate bridges of metal ions in analogous dinuclear units [20]. The magnetic behaviors obtained are in very good concordance with the $\mathrm{Mn} \cdots \mathrm{Mn}$ distances found in $\mathbf{1}$ and $\mathbf{2}$, as a consequence of their structural peculiarities. Polymer 2 exhibits the shortest distance between ions (4.561 $\AA$ ); therefore, it exhibits magnetic interactions. Whereas, magnetic exchange was not found in $\mathbf{1}$, where the metal ions distances fluctuate from 7.012 to $9.885 \AA$. 


\section{Conclusion}

This work reports the easy synthesis and full characterization of two novel Mn coordination polymers formed by fumarato and two different dimethyl-2,2'-bipyridines as co-ligands. In $\mathbf{1}$, the bridging ligand coordinates as $\eta^{1}: \eta^{0}$, yielding a 1D polymer; while in 2 , fum can be found in $\eta^{1}: \eta^{1}$ and $\mu_{2}-\eta^{1}: \eta^{1}$ modes, generating a $2 D$ structure. It is believed that the origin of these dissimilar structures is the degree of steric hindrance around the coordination sphere of $\mathrm{Mn}(\mathrm{II})$ ions, which is provoked by the different position of the methyl groups in the pyridine rings of the dimethyl-2,2'-bipyridines, employed as ancillary ligands. Less hindrance (4dmb) leads to higher structural dimensionality, as in the 2D polymer 2 . The structural differences of compounds $\mathbf{1}$ and $\mathbf{2}$ are also reflected in their thermal and magnetic properties. Thus, polymer 1 exhibits only a paramagnetic behavior; whilst, the negative values obtained for $J$ and $\theta_{C-W}$ are indicative of intra-dimer $\mathrm{Mn}(\mathrm{II})$ weak antiferromagnetic interactions occurring in polymer 2 .

\section{Supplementary data}

CCDC-993491 and 995619 contain supplementary crystallographic data for $\mathbf{1}$ and $\mathbf{2}$, respectively. These data can be obtained free of charge via http://www.ccdc.cam.ac.uk/conts/retrieving/html, or from Cambridge Crystallographic Data Center (CCDC), 12 Union Road, Cambridge CB2 1EZ, UK [Fax: (+44) 1223-336-033; Email: deposit@cdc.cam.ac.uk]. 


\section{Acknowledgments}

Authors are indebted to Dr. Diego Martínez-Otero (CCIQS UAEM-UNAM) and M. en C. Alejandra Nuñez (CCIQS UAEM-UNAM) for single-crystal X-ray diffraction and elemental analyses, respectively. Funding for this work was provided by Universidad Autónoma del Estado de México. This work was also supported by CONACyT project 129293, DGAPAUNAM project IN106014, and ICYTDF, project PICCO. R.E. thanks to A. López, and A. Pompa-Garcia (IIM-UNAM), for help in computational and technical problems.

\section{References}

[1] Robson R (2008) Dalton Trans 5113.

[2] Dua M, Li C-P, Liub C-S, Fang S-M (2013) Coord Chem Rev 257:1282.

[3] Das D, Banerjee R, Mondal R, Howard JAK, Boese R, Desiraju GR (2006) Chem Commun 555.

[4] Desiraju GR, Vittal JJ, Ramanan A (2011) Crystal Engineering-A Text Book, IISc Press and World Scientific, Singapore.

[5] Zhou XH, Li L, Li HH, Li A, Yang T, Huang W (2013) Dalton Trans 42:12403.

[6] Curiel D, Más-Montoya M, Sánchez G (2014) Coord Chem Rev 284:19. 
[7] Shi Z, Zhang L, Gao S, Yang G, Hua J, Gao L, Feng S (2000) Inorg Chem 39:1990.

[8] Bora SJ, Das BK (2012) J Solid State Chem 192:93.

[9] Téllez-López A, Jaramillo-García J, Martínez-Domínguez R, Morales-Luckie RA, Camacho-López MA, Escudero R, Sánchez-Mendieta V (2015) Polyhedron 100:373.

[10] Patrick BO, Reiff WM, Sanchez V, Storr A, Thompson RC (2004) Inorg Chem 43:2330.

[11] Zheng YQ, Lin JL, Chen BY (2003) J Mol Struct 646:151.

[12] Devereux M, McCann M, Leon V, Geraghty M, McKee V, Wikaira J (2000)

Polyhedron 19:1205.

[13] R. D. Hancock (2103) Chem Soc Rev 42:1500.

[14] Alizadeh R, Amani V (2016) Inorg Chim Acta 443:151.

[15] Lopes LB, Corrêa CC, Guedes GP, Vaz MGF, Diniz R, Machado FC (2013) Polyhedron 50:16.

[16] Zhang GM, Li Y, Zou XZ, Zhang JA, Gu JZ, Kirillov AM (2016) Transition Met Chem 41:153. 
[17] APEX 2 software suite. Bruker AXS Inc., Madison, Wisconsin, USA.

[18] Sheldrick GM, SHELX, (2008) Acta Crystallogr Sect A 64:112.

[19] Hübschle CB, Sheldrick GM, Dittrich B, shelXle (2011) Appl Cryst 44:1281.

[20] Wang CC, Gao F, Guo XX, Jing H-P, Wang P, Gao SJ (2016) Transition Met Chem 41:375.

[21] Manna SC, Zangrando E, Drew MGB, Ribas J, Chaudhuri NR (2006) Eur J Inorg Chem 481.

[22] Jin S, Chen W (2007) Inorg Chim Acta 360:3756.

[23] Gu JZ, Kirillov AM, Wu J, Lv DY, Tang Y, Wu JC (2013) Cryst Eng Comm 15:10287.

[24] Gu JZ, Gao ZQ, Tang Y (2012) Cryst Growth Des 12:3312.

[25] Zhao Y, Chang XH, Liu GZ, Ma LF, Wang LY (2015) Cryst Growth Des 15:966.

[26] Bleaney B, Bowers KD (1952) Proc Roy Soc (London) Ser A 214:451.

[27] Dey SK, Hazra M, Thompson LK, Patra A (2016) Inorg Chim Acta 443:224. 
[28] Lou Y, Wang J, Tao Y, Chen J, Mishimab A, Ohba M (2014) Dalton Trans 43:8508. 
Table 1. Crystal data and structure refinement parameters for $\mathbf{1}$ and $\mathbf{2}$.

\begin{tabular}{|c|c|c|}
\hline & 1 & 2 \\
\hline Empirical formula & $\mathrm{C}_{16} \mathrm{H}_{18} \mathrm{MnN}_{2} \mathrm{O}_{6}$ & $\mathrm{C}_{32} \mathrm{H}_{30} \mathrm{Mn}_{2} \mathrm{~N}_{4} \mathrm{O}_{9}$ \\
\hline Formula weight & 389.26 & 724.48 \\
\hline Temperature (K) & \multicolumn{2}{|c|}{$100(2)$} \\
\hline Wavelength $(\AA)$ & \multicolumn{2}{|c|}{0.71073} \\
\hline Crystal system & Monoclinic & Monoclinic \\
\hline Space group & $\mathrm{C} 2 / \mathrm{c}$ & $\mathrm{Cc}$ \\
\hline $\mathrm{a}(\AA)$ & $7.0116(2)$ & $7.8917(3)$ \\
\hline $\mathrm{b}(\AA)$ & $17.3753(4)$ & $20.1889(7)$ \\
\hline $\mathrm{c}(\AA)$ & $13.7100(3)$ & $19.8231(7)$ \\
\hline$\alpha\left(^{\circ}\right)$ & 90 & 90 \\
\hline$\beta\left(^{\circ}\right)$ & $97.8556(5)$ & 98.1991(6) \\
\hline$\gamma\left({ }^{\circ}\right)$ & 90 & 90 \\
\hline Volume $\left(\AA^{3}\right)$ & $1654.60(7)$ & $3126.0(2)$ \\
\hline $\mathrm{Z}$ & 4 & 4 \\
\hline $\mathrm{D}_{\text {calc }}\left(\mathrm{Mg} / \mathrm{m}^{3}\right)$ & 1.563 & 1.539 \\
\hline Absorption coefficient $\left(\mathrm{mm}^{-1}\right)$ & 0.834 & 0.870 \\
\hline $\mathrm{F}(000)$ & 804 & 1488 \\
\hline Crystal size $\left(\mathrm{mm}^{3}\right)$ & $0.216 \times 0.203 \times 0.168$ & $0.349 \times 0.193 \times 0.162$ \\
\hline Theta range for data collection $\left(^{\circ}\right)$ & 2.344 to 26.021 & 2.017 to 25.349 \\
\hline Index ranges & $\begin{array}{c}-8<=\mathrm{h}<=8,21<=\mathrm{k}<=21,- \\
16<=\mathrm{l}<=16\end{array}$ & $\begin{array}{c}-9<=\mathrm{h}<=9,-24<=\mathrm{k}<=24,- \\
23<=\mathrm{l}<=23\end{array}$ \\
\hline Reflections collected & 11994 & 28301 \\
\hline Independent reflections & $1623[\mathrm{R}(\mathrm{int})=0.0235]$ & $5730[\mathrm{R}($ int $)=0.0200]$ \\
\hline Refinement method & \multicolumn{2}{|c|}{ Full-matrix least-squares on $\mathrm{F}^{2}$} \\
\hline Data/restraints/parameters & $1623 / 94 / 158$ & $5730 / 23 / 453$ \\
\hline Goodness-of-fit on $\mathrm{F}^{2}$ & 1.068 & 1.065 \\
\hline Final $\mathrm{R}$ indices [I>2sigma(I)] & $\mathrm{R} 1=0.0197, \mathrm{wR} 2=0.0509$ & $\mathrm{R} 1=0.0216, \mathrm{wR} 2=0.0609$ \\
\hline $\mathrm{R}$ indices (all data) & $\mathrm{R} 1=0.0202, \mathrm{wR} 2=0.0513$ & $\mathrm{R} 1=0.0218, \mathrm{wR} 2=0.0610$ \\
\hline Largest diff. peak and hole e. $\AA^{-3}$ & 0.292 and -0.235 & 0.458 and -0.202 \\
\hline
\end{tabular}


Table 2. Selected bond distances $(\AA)$ and angles $\left({ }^{\circ}\right)$ for $\mathbf{1}$.

\begin{tabular}{|c|c|c|c|c|}
\hline \multicolumn{5}{|c|}{ Bond lengths $(\AA)$} \\
\hline $\mathrm{Mn}(1)-\mathrm{O}(1) \# 1$ & $2.161(5)$ & & $\mathrm{Mn}(1)-\mathrm{O}(3) \# 1$ & $2.1665(9)$ \\
\hline $\mathrm{Mn}(1)-\mathrm{O}(1)$ & $2.161(5)$ & & $\operatorname{Mn}(1)-N(1)$ & $2.2818(10)$ \\
\hline $\mathrm{Mn}(1)-\mathrm{O}(1 \mathrm{~A})$ & $2.163(5)$ & & $\mathrm{Mn}(1)-\mathrm{N}(1) \# 1$ & $2.2818(10)$ \\
\hline $\mathrm{Mn}(1)-\mathrm{O}(1 \mathrm{~A}) \# 1$ & $2.163(5)$ & & & \\
\hline $\mathrm{Mn}(1)-\mathrm{O}(3)$ & $2.1665(9)$ & & & \\
\hline \multicolumn{5}{|c|}{ Angles $\left({ }^{\circ}\right)$} \\
\hline $\mathrm{O}(1) \# 1-\mathrm{Mn}(1)-\mathrm{O}(1)$ & $163.2(10)$ & & $\mathrm{O}(1)-\mathrm{Mn}(1)-\mathrm{N}(1)$ & $103.4(4)$ \\
\hline $\mathrm{O}(1 \mathrm{~A})-\mathrm{Mn}(1)-\mathrm{O}(1 \mathrm{~A}) \# 1$ & $167.0(10)$ & & $\mathrm{O}(1 \mathrm{~A})-\mathrm{Mn}(1)-\mathrm{N}(1)$ & $98.3(4)$ \\
\hline $\mathrm{O}(1) \# 1-\mathrm{Mn}(1)-\mathrm{O}(3)$ & $85.8(5)$ & & $\mathrm{O}(1 \mathrm{~A}) \# 1-\mathrm{Mn}(1)-\mathrm{N}(1)$ & $92.2(5)$ \\
\hline $\mathrm{O}(1)-\mathrm{Mn}(1)-\mathrm{O}(3)$ & $83.5(3)$ & & $\mathrm{O}(3)-\mathrm{Mn}(1)-\mathrm{N}(1)$ & $164.20(4)$ \\
\hline $\mathrm{O}(1 \mathrm{~A})-\mathrm{Mn}(1)-\mathrm{O}(3)$ & $89.3(4)$ & & $\mathrm{O}(3) \# 1-\mathrm{Mn}(1)-\mathrm{N}(1)$ & $94.05(4)$ \\
\hline $\mathrm{O}(1 \mathrm{~A}) \# 1-\mathrm{Mn}(1)-\mathrm{O}(3)$ & $82.4(5)$ & & $\mathrm{O}(1) \# 1-\mathrm{Mn}(1)-\mathrm{N}(1) \# 1$ & $103.4(4)$ \\
\hline $\mathrm{O}(1) \# 1-\mathrm{Mn}(1)-\mathrm{O}(3) \# 1$ & $83.5(3)$ & & $\mathrm{O}(1)-\mathrm{Mn}(1)-\mathrm{N}(1) \# 1$ & $90.3(5)$ \\
\hline $\mathrm{O}(1)-\mathrm{Mn}(1)-\mathrm{O}(3) \# 1$ & $85.8(5)$ & & $\mathrm{O}(1 \mathrm{~A})-\mathrm{Mn}(1)-\mathrm{N}(1) \# 1$ & $92.2(5)$ \\
\hline $\mathrm{O}(1 \mathrm{~A})-\mathrm{Mn}(1)-\mathrm{O}(3) \# 1$ & $82.4(5)$ & & $\mathrm{O}(1 \mathrm{~A}) \# 1-\mathrm{Mn}(1)-\mathrm{N}(1) \# 1$ & $98.3(4)$ \\
\hline $\mathrm{O}(1 \mathrm{~A}) \# 1-\mathrm{Mn}(1)-\mathrm{O}(3) \# 1$ & $89.3(4)$ & & $\mathrm{O}(3)-\mathrm{Mn}(1)-\mathrm{N}(1) \# 1$ & $94.05(4)$ \\
\hline $\mathrm{O}(3)-\mathrm{Mn}(1)-\mathrm{O}(3) \# 1$ & $100.69(5)$ & & $\mathrm{O}(3) \# 1-\mathrm{Mn}(1)-\mathrm{N}(1) \# 1$ & $164.20(4)$ \\
\hline $\mathrm{O}(1) \# 1-\mathrm{Mn}(1)-\mathrm{N}(1)$ & $90.3(5)$ & & $\mathrm{N}(1)-\mathrm{Mn}(1)-\mathrm{N}(1) \# 1$ & $71.97(5)$ \\
\hline D-H...A & $d(D-H)$ & $\mathrm{d}(\mathrm{H} \ldots \mathrm{A})$ & $\mathrm{d}(\mathrm{D} \ldots \mathrm{A})$ & $<(\mathrm{DHA})$ \\
\hline $\mathrm{O}(3)-\mathrm{H}(3 \mathrm{~A}) \ldots \mathrm{O}(2 \mathrm{~A})$ & $0.852(13)$ & $2.018(9)$ & $2.7158(19)$ & $138.6(16)$ \\
\hline $\mathrm{O}(3)-\mathrm{H}(3 \mathrm{~A}) \ldots \mathrm{O}(2 \mathrm{~A}) \# 3$ & $0.852(13)$ & $1.845(16)$ & $2.6536(19)$ & $158.0(15)$ \\
\hline $\mathrm{O}(3)-\mathrm{H}(3 \mathrm{~B}) \ldots \mathrm{O}(2) \# 1$ & $0.811(15)$ & $2.106(19)$ & $2.7275(19)$ & 133(2) \\
\hline $\mathrm{O}(3)-\mathrm{H}(3 \mathrm{~B}) \ldots \mathrm{O}(2) \# 4$ & $0.811(15)$ & $1.902(16)$ & $2.6879(19)$ & $163(2)$ \\
\hline
\end{tabular}


Table 3. Selected bond distances $(\AA)$ and angles $\left({ }^{\circ}\right)$ for $\mathbf{2}$.

\begin{tabular}{|c|c|c|c|}
\hline \multicolumn{4}{|c|}{ Bond lengths $(\AA)$} \\
\hline $\mathrm{Mn}(1)-\mathrm{O}(4) \# 1$ & $2.111(2)$ & $\mathrm{Mn}(2)-\mathrm{O}(2) \# 3$ & $2.084(2)$ \\
\hline $\mathrm{Mn}(1)-\mathrm{O}(1)$ & $2.111(2)$ & $\mathrm{Mn}(2)-\mathrm{O}(3)$ & $2.106(2)$ \\
\hline $\mathrm{Mn}(1)-\mathrm{O}(7) \# 2$ & $2.232(2)$ & $\mathrm{Mn}(2)-\mathrm{O}(5)$ & $2.236(2)$ \\
\hline $\mathrm{Mn}(1)-\mathrm{N}(2)$ & $2.253(3)$ & $\mathrm{Mn}(2)-\mathrm{N}(3)$ & $2.240(3)$ \\
\hline $\mathrm{Mn}(1)-\mathrm{N}(1)$ & $2.264(3)$ & $\operatorname{Mn}(2)-\mathrm{N}(4)$ & $2.265(3)$ \\
\hline $\mathrm{Mn}(1)-\mathrm{O}(8) \# 2$ & $2.315(2)$ & $\mathrm{Mn}(2)-\mathrm{O}(6)$ & $2.317(2)$ \\
\hline $\mathrm{Mn}(1)-\mathrm{C}(33) \# 2$ & $2.599(3)$ & $\operatorname{Mn}(2)-C(29)$ & $2.607(3)$ \\
\hline \multicolumn{4}{|c|}{ Angles $\left({ }^{\circ}\right)$} \\
\hline $\mathrm{O}(4) \# 1-\mathrm{Mn}(1)-\mathrm{O}(1)$ & $99.90(9)$ & $\mathrm{O}(2) \# 3-\mathrm{Mn}(2)-\mathrm{O}(5)$ & $102.25(9)$ \\
\hline $\mathrm{O}(4) \# 1-\mathrm{Mn}(1)-\mathrm{O}(7) \# 2$ & $94.81(9)$ & $\mathrm{O}(3)-\mathrm{Mn}(2)-\mathrm{O}(5)$ & $97.65(9)$ \\
\hline $\mathrm{O}(1)-\mathrm{Mn}(1)-\mathrm{O}(7) \# 2$ & $94.49(8)$ & $\mathrm{O}(2) \# 3-\mathrm{Mn}(2)-\mathrm{N}(3)$ & $88.57(9)$ \\
\hline $\mathrm{O}(4) \# 1-\mathrm{Mn}(1)-\mathrm{N}(2)$ & $170.45(10)$ & $\mathrm{O}(3)-\mathrm{Mn}(2)-\mathrm{N}(3)$ & $104.90(9)$ \\
\hline $\mathrm{O}(1)-\mathrm{Mn}(1)-\mathrm{N}(2)$ & $86.75(9)$ & $\mathrm{O}(5)-\mathrm{Mn}(2)-\mathrm{N}(3)$ & $152.11(9)$ \\
\hline $\mathrm{O}(7) \# 2-\mathrm{Mn}(1)-\mathrm{N}(2)$ & $91.47(9)$ & $\mathrm{O}(2) \# 3-\mathrm{Mn}(2)-\mathrm{N}(4)$ & $160.35(10)$ \\
\hline $\mathrm{O}(4) \# 1-\mathrm{Mn}(1)-\mathrm{N}(1)$ & $99.11(9)$ & $\mathrm{O}(3)-\mathrm{Mn}(2)-\mathrm{N}(4)$ & $85.85(9)$ \\
\hline $\mathrm{O}(1)-\mathrm{Mn}(1)-\mathrm{N}(1)$ & $107.86(9)$ & $\mathrm{O}(5)-\mathrm{Mn}(2)-\mathrm{N}(4)$ & $93.71(9)$ \\
\hline $\mathrm{O}(7) \# 2-\mathrm{Mn}(1)-\mathrm{N}(1)$ & 151.03(9) & $\mathrm{N}(3)-\mathrm{Mn}(2)-\mathrm{N}(4)$ & $72.11(9)$ \\
\hline $\mathrm{N}(2)-\mathrm{Mn}(1)-\mathrm{N}(1)$ & $72.17(9)$ & $\mathrm{O}(2) \# 3-\mathrm{Mn}(2)-\mathrm{O}(6)$ & $93.66(9)$ \\
\hline $\mathrm{O}(4) \# 1-\mathrm{Mn}(1)-\mathrm{O}(8) \# 2$ & $90.29(8)$ & $\mathrm{O}(3)-\mathrm{Mn}(2)-\mathrm{O}(6)$ & $153.31(8)$ \\
\hline $\mathrm{O}(1)-\mathrm{Mn}(1)-\mathrm{O}(8) \# 2$ & $151.69(8)$ & $\mathrm{O}(5)-\mathrm{Mn}(2)-\mathrm{O}(6)$ & $58.06(8)$ \\
\hline $\mathrm{O}(7) \# 2-\mathrm{Mn}(1)-\mathrm{O}(8) \# 2$ & $58.14(8)$ & $\mathrm{N}(3)-\mathrm{Mn}(2)-\mathrm{O}(6)$ & $96.05(9)$ \\
\hline $\mathrm{N}(2)-\mathrm{Mn}(1)-\mathrm{O}(8) \# 2$ & $86.91(9)$ & $\mathrm{N}(4)-\mathrm{Mn}(2)-\mathrm{O}(6)$ & $85.04(9)$ \\
\hline $\mathrm{N}(1)-\mathrm{Mn}(1)-\mathrm{O}(8) \# 2$ & $96.34(9)$ & $\mathrm{O}(2) \# 3-\mathrm{Mn}(2)-\mathrm{C}(29)$ & $99.91(9)$ \\
\hline $\mathrm{O}(4) \# 1-\mathrm{Mn}(1)-\mathrm{C}(33) \# 2$ & $93.08(9)$ & $\mathrm{O}(3)-\mathrm{Mn}(2)-\mathrm{C}(29)$ & $126.00(9)$ \\
\hline $\mathrm{O}(1)-\mathrm{Mn}(1)-\mathrm{C}(33) \# 2$ & $123.34(9)$ & $\mathrm{O}(5)-\mathrm{Mn}(2)-\mathrm{C}(29)$ & $29.34(9)$ \\
\hline $\mathrm{O}(7) \# 2-\mathrm{Mn}(1)-\mathrm{C}(33) \# 2$ & 29.18(9) & $\mathrm{N}(3)-\mathrm{Mn}(2)-\mathrm{C}(29)$ & $123.95(10)$ \\
\hline $\mathrm{N}(2)-\mathrm{Mn}(1)-\mathrm{C}(33) \# 2$ & $88.88(9)$ & $\mathrm{N}(4)-\mathrm{Mn}(2)-\mathrm{C}(29)$ & $88.37(9)$ \\
\hline $\mathrm{N}(1)-\mathrm{Mn}(1)-\mathrm{C}(33) \# 2$ & $124.15(9)$ & $\mathrm{O}(6)-\mathrm{Mn}(2)-\mathrm{C}(29)$ & $28.75(9)$ \\
\hline $\mathrm{O}(8) \# 2-\mathrm{Mn}(1)-\mathrm{C}(33) \# 2$ & $28.96(9)$ & & \\
\hline $\mathrm{O}(2) \# 3-\mathrm{Mn}(2)-\mathrm{O}(3)$ & 103.07(9) & & \\
\hline
\end{tabular}




\begin{tabular}{lcccc}
\hline $\mathrm{D}-\mathrm{H} \ldots \mathrm{A}$ & $\mathrm{d}(\mathrm{D}-\mathrm{H})$ & $\mathrm{d}(\mathrm{H} \ldots \mathrm{A})$ & $\mathrm{d}(\mathrm{D} \ldots \mathrm{A})$ & $<(\mathrm{DHA})$ \\
\hline $\mathrm{O}(9)-\mathrm{H}(9 \mathrm{~A}) \ldots \mathrm{O}(5)$ & $0.828(14)$ & $2.21(2)$ & $3.027(5)$ & $167(5)$ \\
$\mathrm{O}(9)-\mathrm{H}(9 \mathrm{~B}) \ldots \mathrm{O}(4)$ & $0.831(16)$ & $2.49(2)$ & $3.271(5)$ & $158(5)$ \\
$\mathrm{O}(9 \mathrm{~A})-\mathrm{H}(9 \mathrm{C}) \ldots \mathrm{O}(5)$ & $0.891(19)$ & $2.03(3)$ & $2.857(10)$ & $153(6)$ \\
$\mathrm{O}(9 \mathrm{~B})-\mathrm{H}(9 \mathrm{E}) \ldots \mathrm{O}(4)$ & $0.96(3)$ & $2.03(3)$ & $2.878(10)$ & $147(4)$ \\
\hline
\end{tabular}

Symmetry transformations used to generate equivalent atoms:

$\# 1 \mathrm{x}+1, \mathrm{y}, \mathrm{z} \quad \# 2 \mathrm{x}+2,-\mathrm{y}+1, \mathrm{z}+1 / 2 \quad \# 3 \mathrm{x}-1, \mathrm{y}, \mathrm{z} \quad \# 4 \mathrm{x}-2,-\mathrm{y}+1, \mathrm{z}-1 / 2$ 


\section{Figure captions}

Figure 1. Molecular structure of $\left\{\mathrm{Mn}(\mathrm{fum})(5 \mathrm{dmb})\left(\mathrm{H}_{2} \mathrm{O}\right)_{2}\right\}_{\mathrm{n}}$ (1) (a); 1D zig-zag polymer chain of 1, looking almost down $c$ axis; hydrogens omitted for clarity (b).

Figure 2. Hydrogen bonding main connections in 1, view looking down $b$ axis; 5dmb ligand is omitted for clarity (a). 2D supramolecular wrinkle-sheet type packing of $\mathbf{1}$, view looking down almost $b$ axis; $5 \mathrm{dmb}$ ligand is omitted for clarity (b).

Figure 3. Molecular structure of $\left\{\left[\mathrm{Mn}_{2}(\mathrm{fum})_{2}(4 \mathrm{dmb})_{2}\right] \cdot \mathrm{H}_{2} \mathrm{O}\right\}_{\mathrm{n}}(2)$ (a). Detail of coordination modes of fum ligand in 2, view looking down $b$ axis; $4 \mathrm{dmb}$ ligand and hydrogens are omitted for clarity (b).

Figure 4. 2D supramolecular array of 2, view looking down almost $b$ axis; hydrogens and 4dmb ligand are omitted for clarity (a). 2D supramolecular wrinkle-sheet type packing of $\mathbf{2}$, view looking down almost $a$ axis (b).

Figure 5. TGA plots for polymers 1 and 2.

Figure 6. $\chi T$ vs. $T$ plots for 1 and 2. 
Figure 7. $\chi$ vs. $T$ plot (a) and $\chi^{-1}$ vs. $T$ plot (b) for 1.

Figure 8. $\chi$ vs. $T$ plot (a) and $\chi^{-1}$ vs. $T$ plot (b) for 2. 

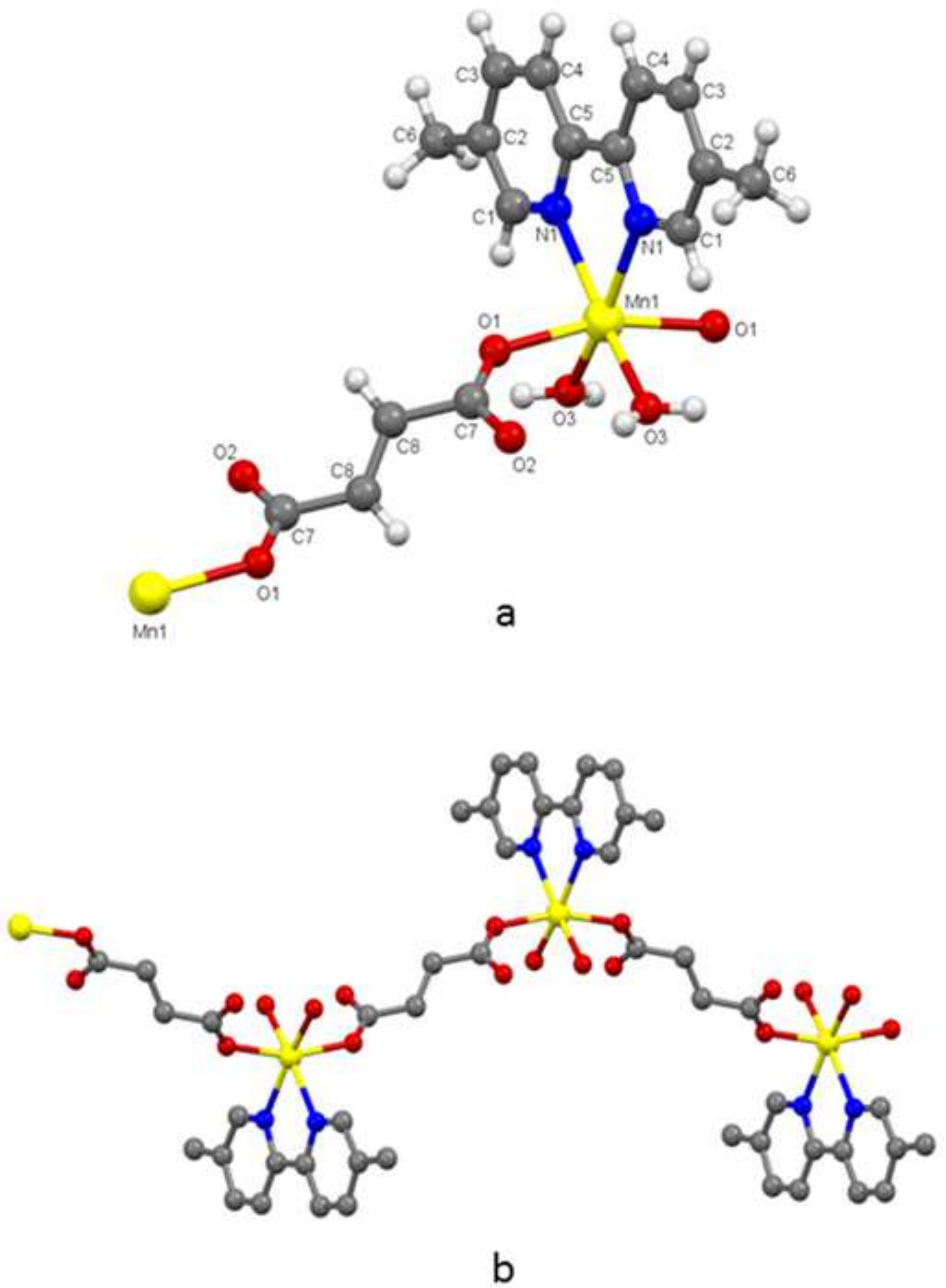

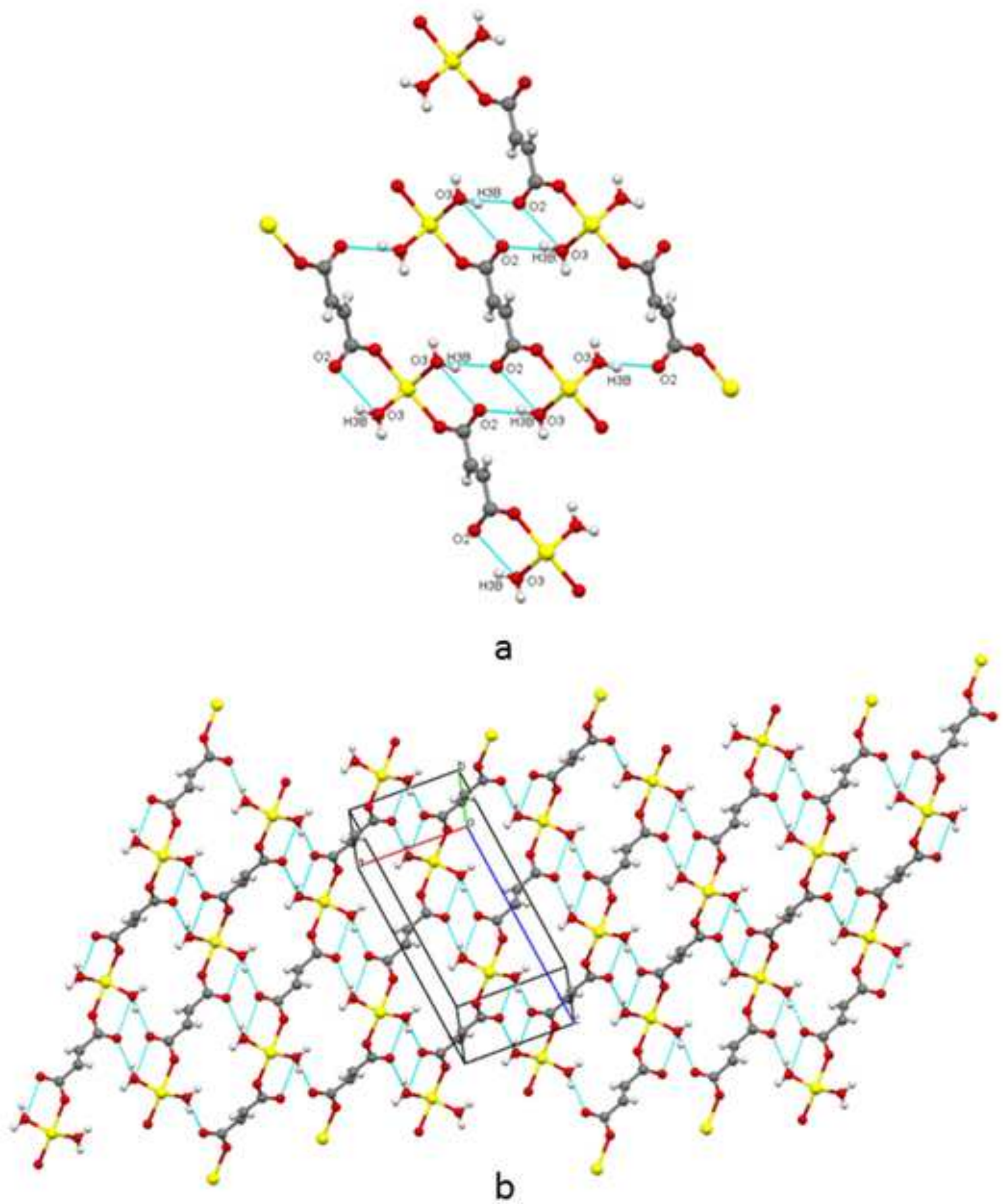

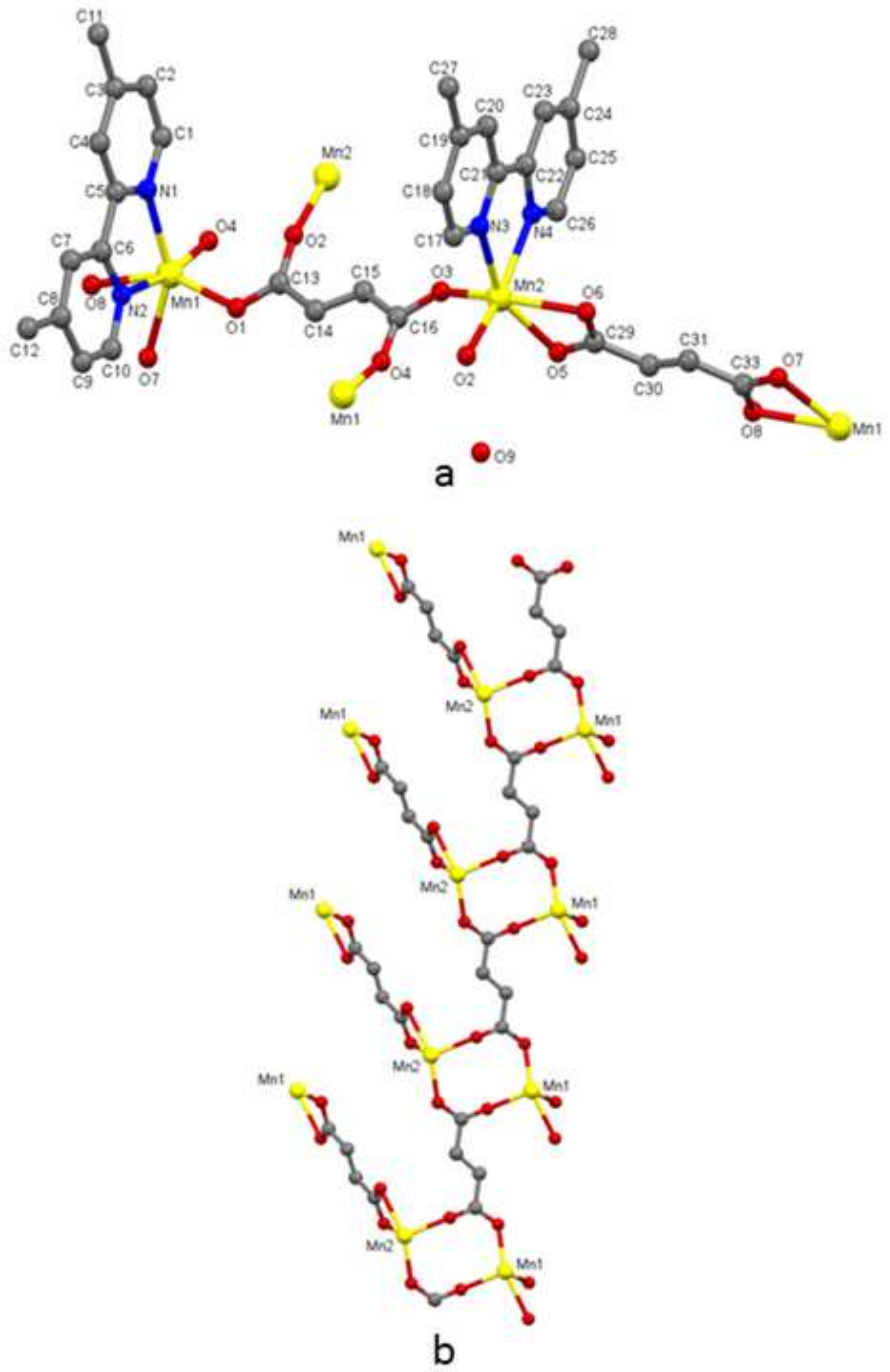

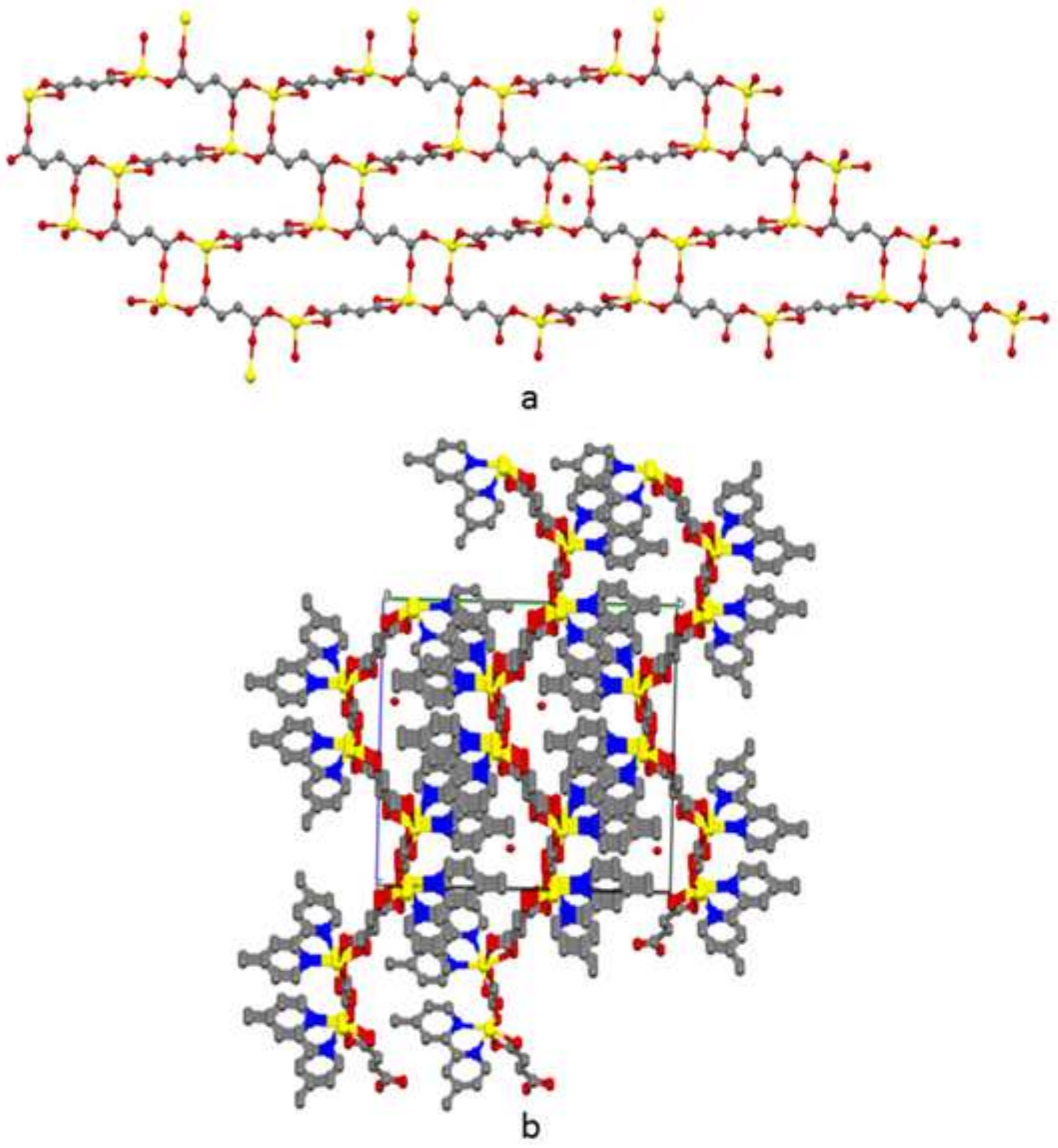
Click here to download Figure Figure 5.tif $\underline{\underline{ }}$

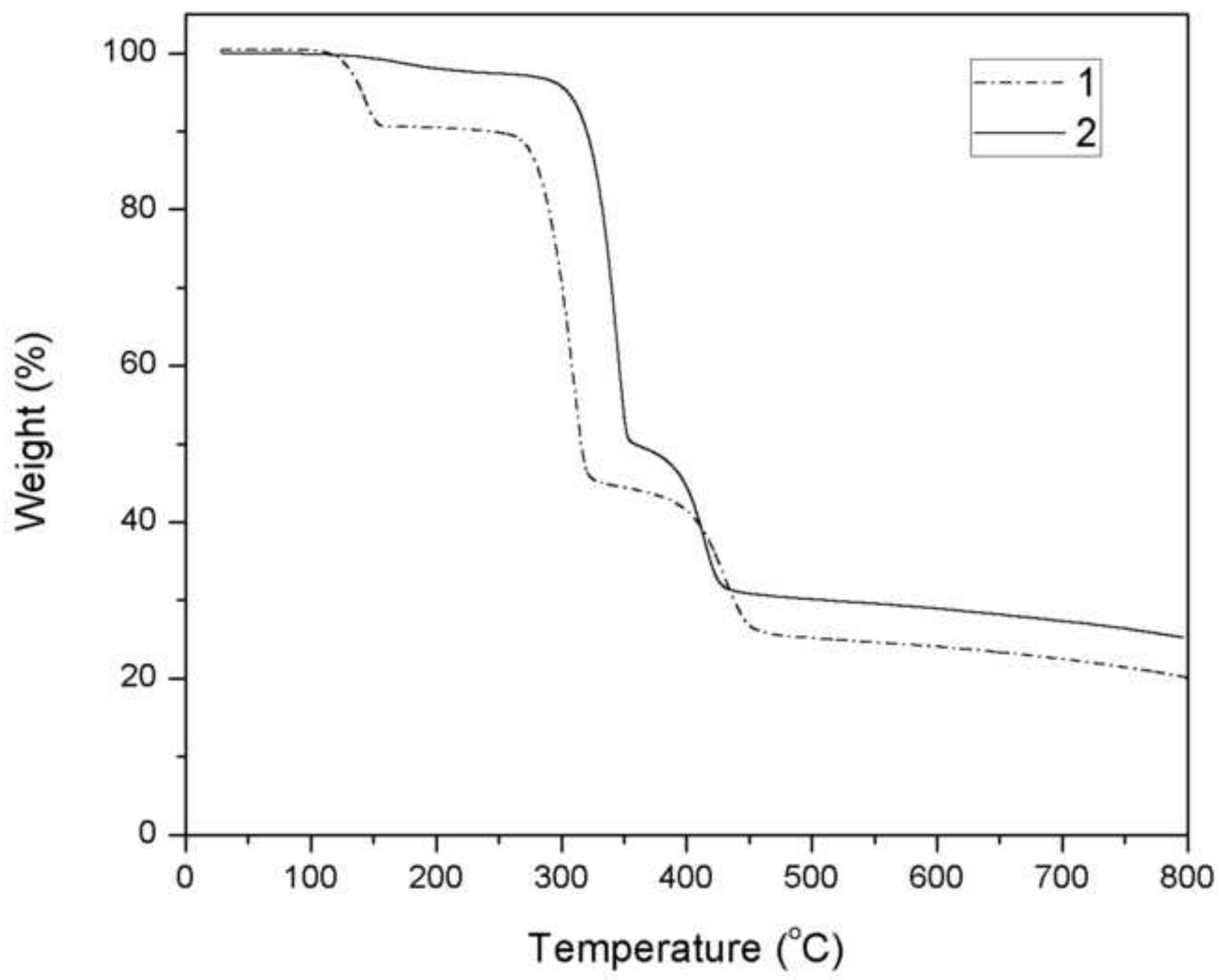


Click here to download Figure Figure 6.tif $\underline{\underline{ }}$

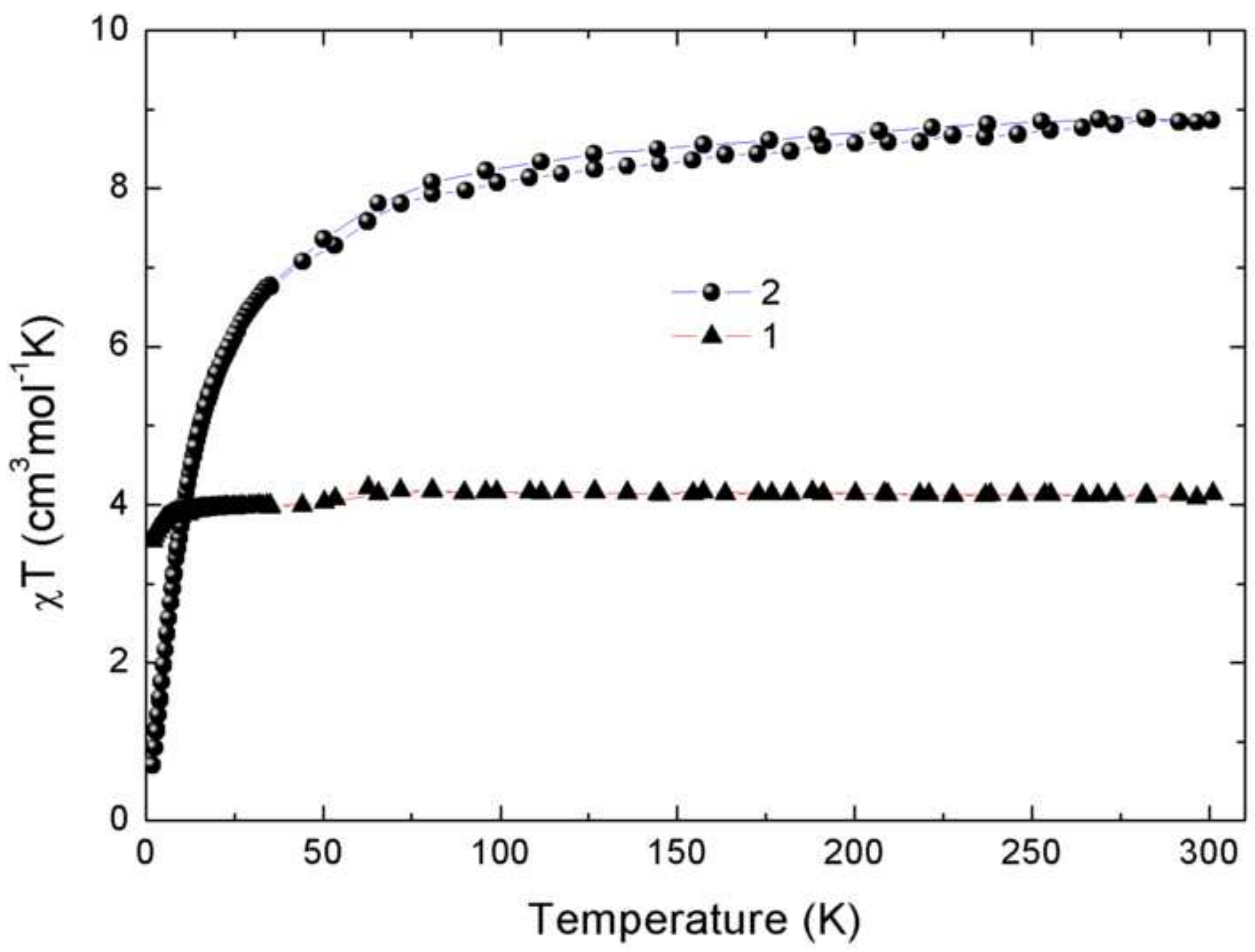



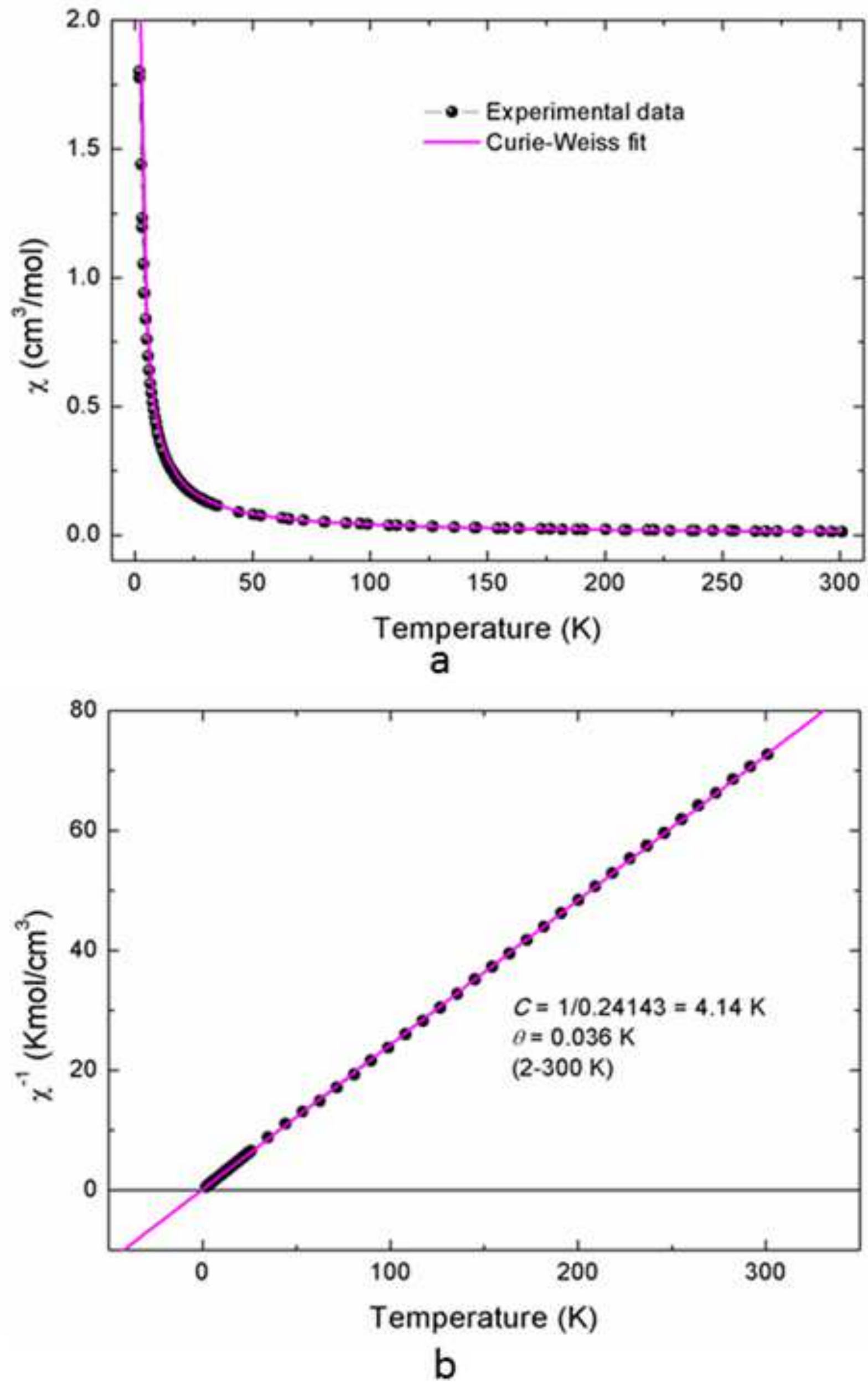

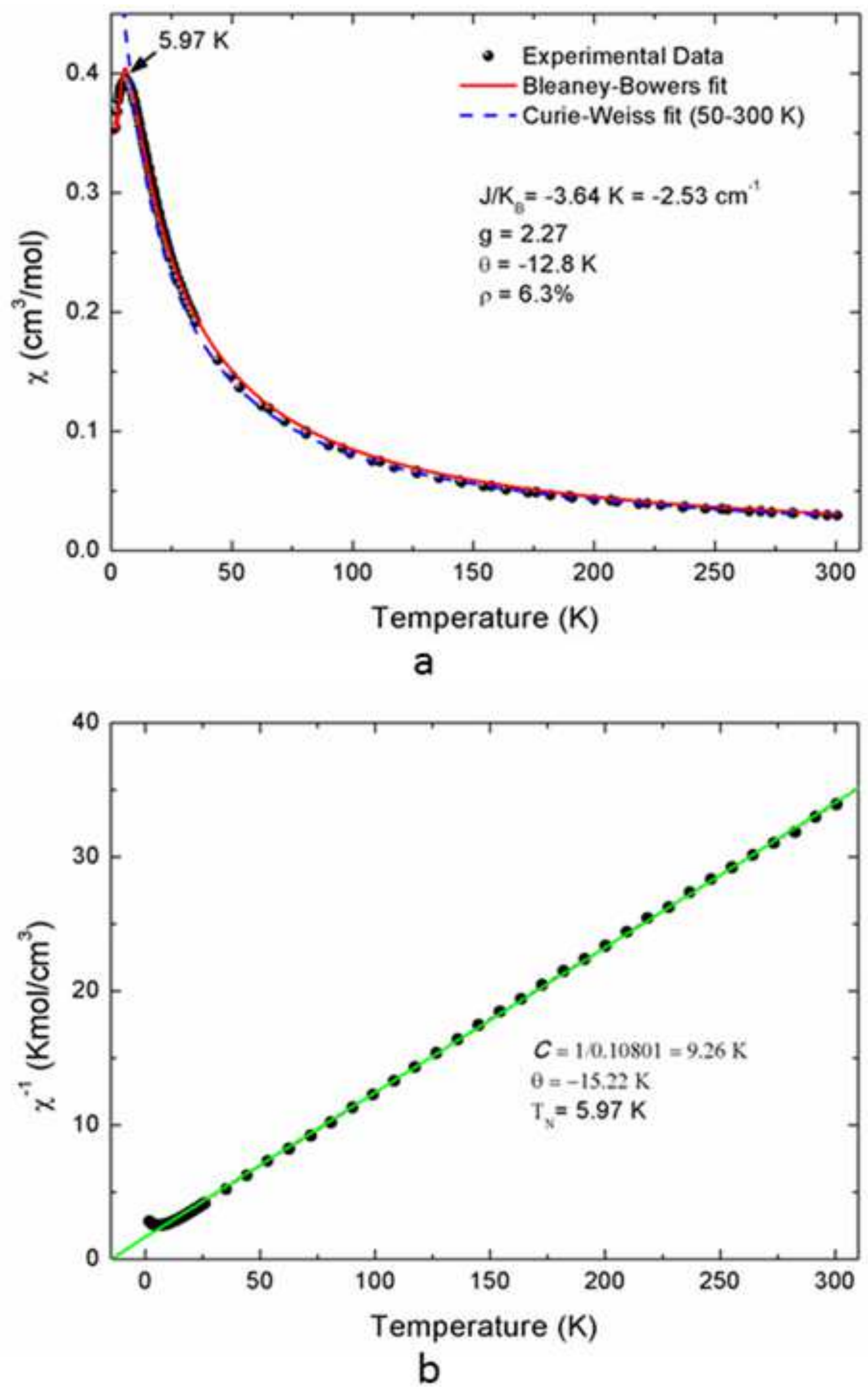


\section{checkCIF/PLATON report}

Structure factors have been supplied for datablock(s) mo_079mlra14_new_0m

THIS REPORT IS FOR GUIDANCE ONLY. IF USED AS PART OF A REVIEW PROCEDURE FOR PUBLICATION, IT SHOULD NOT REPLACE THE EXPERTISE OF AN EXPERIENCED CRYSTALLOGRAPHIC REFEREE.

No syntax errors found. CIF dictionary Interpreting this report

\section{Datablock: mo_079mlra14_new_0m}

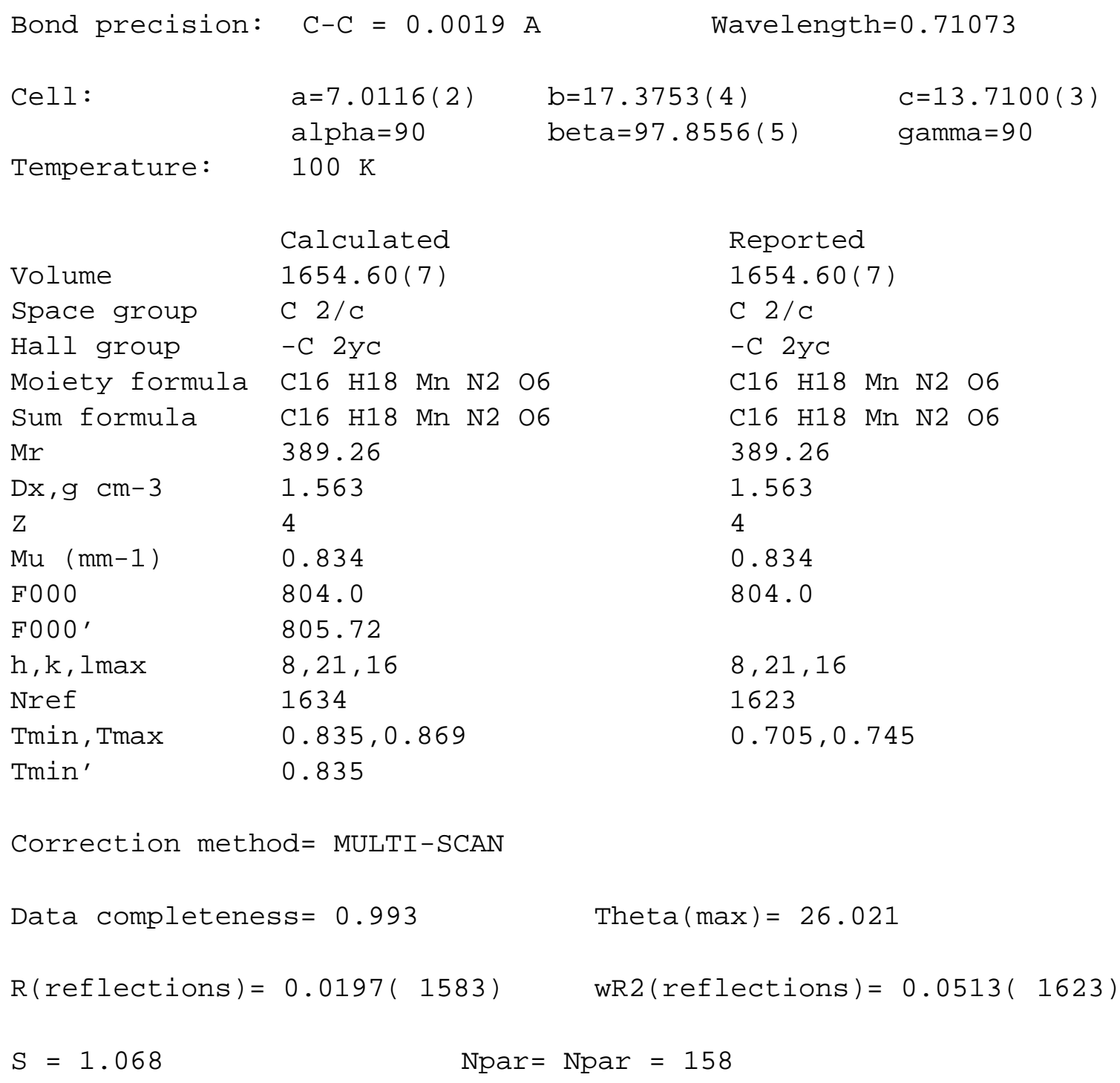

The following ALERTS were generated. Each ALERT has the format test-name_ALERT_alert-type_alert-level.

Click on the hyperlinks for more details of the test. 
Alert level $\mathrm{C}$

PLAT222_ALERT_3_C Large Non-Solvent H Uiso(max)/Uiso(min) ..

PLAT911_ALERT_3_C Missing \# FCF Refl Between THmin \& $S T h / L=0.600$

PLAT913_ALERT_3_C Missing \# of Very strong Reflections in FCF ....

4.4 Ratio

11 Why ?

2 Note

Alert level $\mathbf{G}$

PLAT002_ALERT_2_G Number of Distance or Angle Restraints on AtSite

7 Note

PLAT003_ALERT_2_G Number of Uiso or Uij Restrained non-H Atoms ...

PLAT232_ALERT_2_G Hirshfeld Test Diff (M-X) Mn1 - 03 ..

PLAT232_ALERT_2_G Hirshfeld Test Diff (M-X) Mn1 - - N1 ..

PLAT301_ALERT_3_G Main Residue Disorder ......... Percentage $=$ PLAT811_ALERT_5_G No ADDSYM Analysis: Too Many Excluded Atoms .... PLAT860_ALERT_3_G Number of Least-Squares Restraints ...........
8 Why ?

$5.6 \mathrm{su}$

$7.8 \mathrm{su}$

32 Note

! Info

94 Note

0 ALERT level $\mathbf{A}=$ Most likely a serious problem - resolve or explain

0 ALERT level $\mathbf{B}=\mathrm{A}$ potentially serious problem, consider carefully

3 ALERT level $\mathbf{C}=$ Check. Ensure it is not caused by an omission or oversight

7 ALERT level $\mathbf{G}=$ General information/check it is not something unexpected

0 ALERT type 1 CIF construction/syntax error, inconsistent or missing data

4 ALERT type 2 Indicator that the structure model may be wrong or deficient

5 ALERT type 3 Indicator that the structure quality may be low

0 ALERT type 4 Improvement, methodology, query or suggestion

1 ALERT type 5 Informative message, check

It is advisable to attempt to resolve as many as possible of the alerts in all categories. Often the minor alerts point to easily fixed oversights, errors and omissions in your CIF or refinement strategy, so attention to these fine details can be worthwhile. In order to resolve some of the more serious problems it may be necessary to carry out additional measurements or structure refinements. However, the purpose of your study may justify the reported deviations and the more serious of these should normally be commented upon in the discussion or experimental section of a paper or in the "special_details" fields of the CIF. checkCIF was carefully designed to identify outliers and unusual parameters, but every test has its limitations and alerts that are not important in a particular case may appear. Conversely, the absence of alerts does not guarantee there are no aspects of the results needing attention. It is up to the individual to critically assess their own results and, if necessary, seek expert advice.

\section{Publication of your CIF in IUCr journals}

A basic structural check has been run on your CIF. These basic checks will be run on all CIFs submitted for publication in IUCr journals (Acta Crystallographica, Journal of Applied Crystallography, Journal of Synchrotron Radiation); however, if you intend to submit to Acta Crystallographica Section $C$ or $E$, you should make sure that full publication checks are run on the final version of your CIF prior to submission.

\section{Publication of your CIF in other journals}

Please refer to the Notes for Authors of the relevant journal for any special instructions relating to CIF submission. 
PLATON version of $05 / 02 / 2014$; check.def file version of $05 / 02 / 2014$

Datablock mo_079mlra14_new_0m - ellipsoid plot

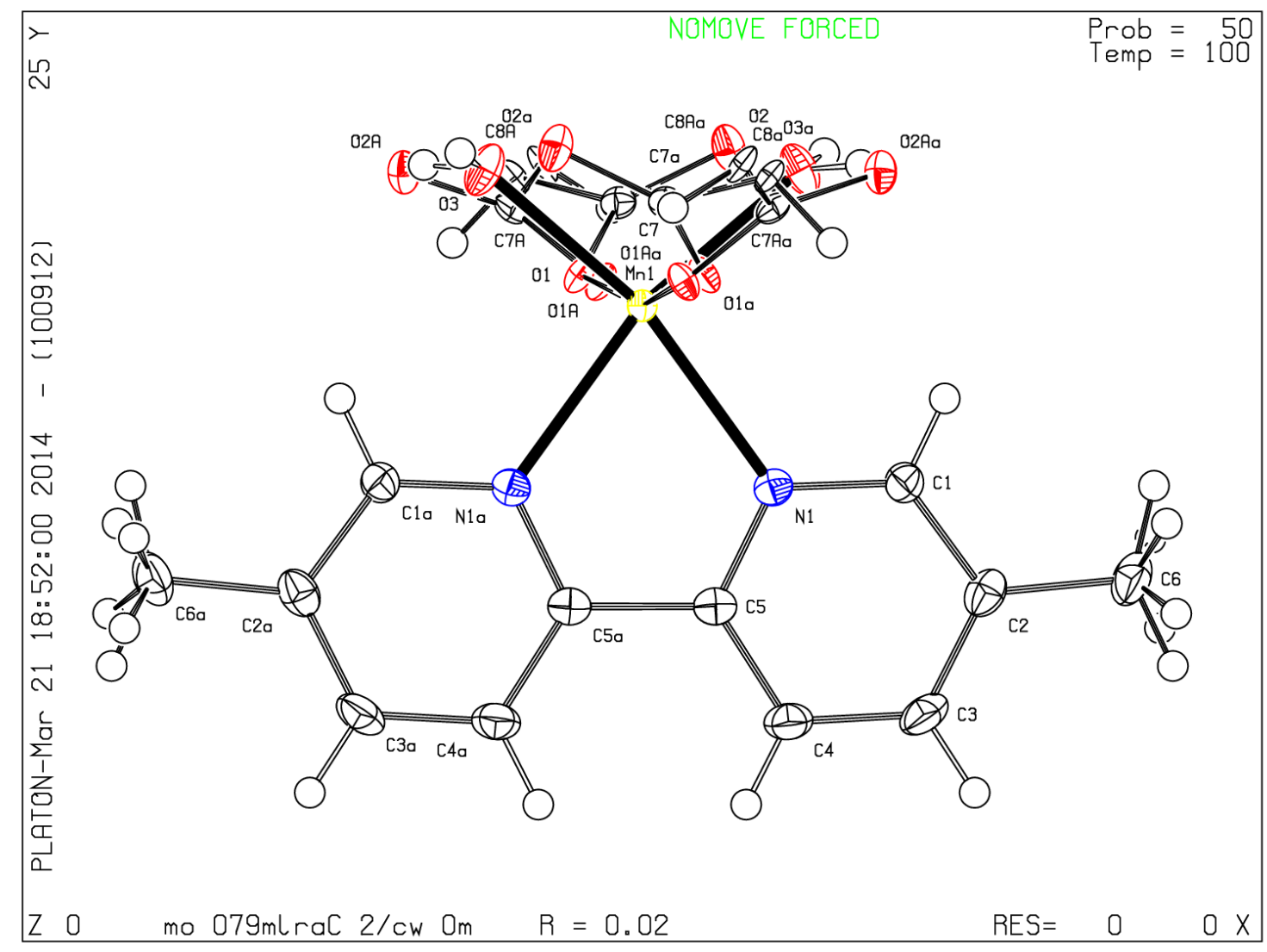




\section{checkCIF/PLATON report}

Structure factors have been supplied for datablock(s) mo_081mlra14_0m

THIS REPORT IS FOR GUIDANCE ONLY. IF USED AS PART OF A REVIEW PROCEDURE FOR PUBLICATION, IT SHOULD NOT REPLACE THE EXPERTISE OF AN EXPERIENCED CRYSTALLOGRAPHIC REFEREE.

No syntax errors found. CIF dictionary Interpreting this report

\section{Datablock: mo_081mlra14_0m}

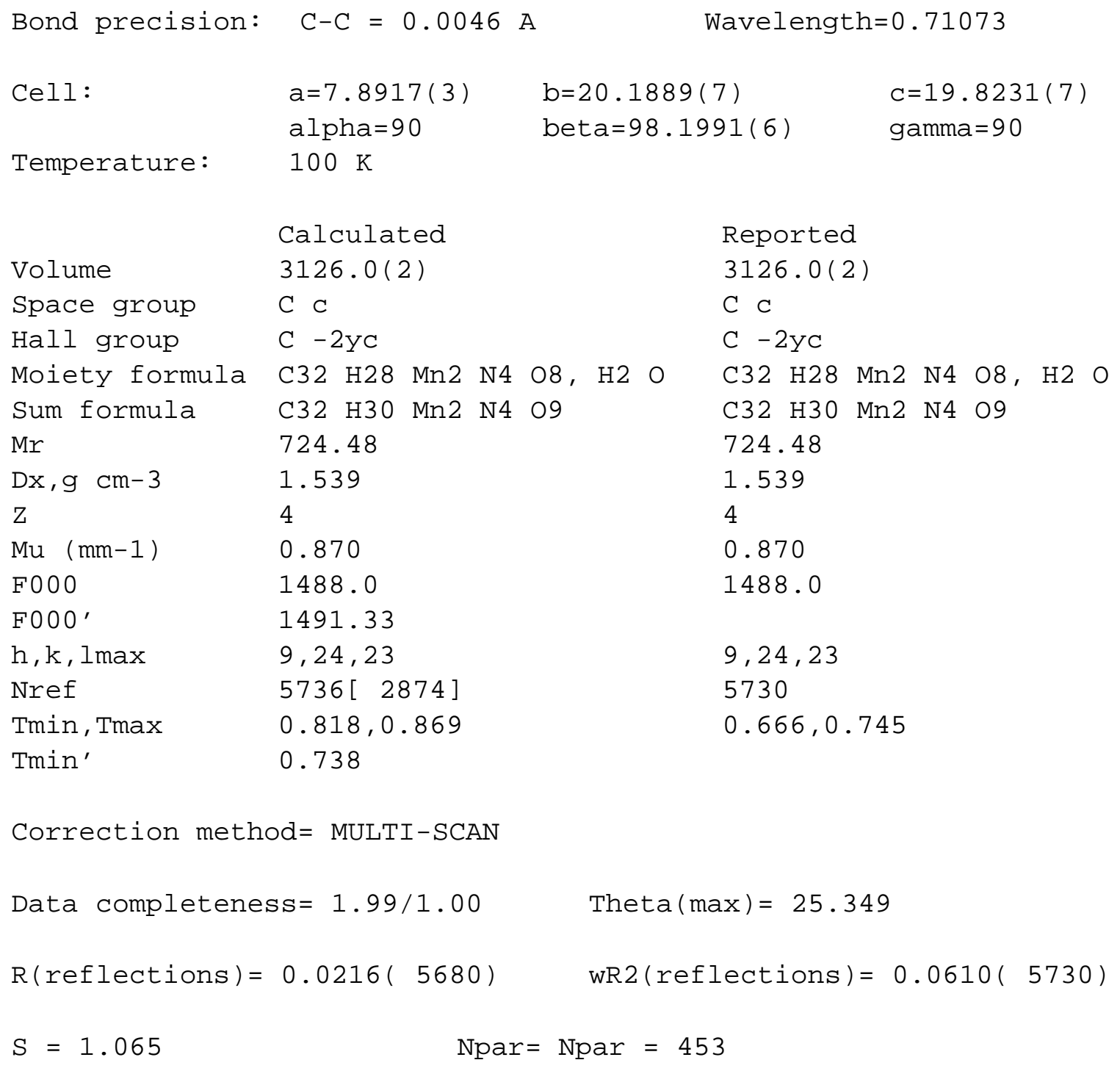


Alert level $C$

PLAT090_ALERT_3_C PLAT094_ALERT_2_C PLAT220_ALERT_2_C PLAT222_ALERT_3_C PLAT911_ALERT_3_C PLAT913_ALERT_3_C
Poor Data / Parameter Ratio (Zmax > 18) ...... Ratio of Maximum / Minimum Residual Density ... Large Non-Solvent C Ueq(max)/Ueq(min) Range Large Non-Solvent $\mathrm{H} \quad \mathrm{Uiso}(\max ) / \mathrm{Uiso}(\mathrm{min})$.. Missing \# FCF Refl Between THmin \& STh/L= 0.600 Missing \# of Very Strong Reflections in FCF ...
6.34 Note

2.27 Why ?

3. 4 Ratio

4.2 Ratio

2 Why ?

1 Note

Alert level $\mathbf{G}$

PLAT002_ALERT_2_G Number of Distance or Angle Restraints on AtSite

PLAT004_ALERT_5_G Polymeric Structure Found with Dimension .......

PLAT302_ALERT_4_G Anion/Solvent Disorder ......... Percentage $=$

PLAT764_ALERT_4_G Overcomplete CIF Bond List Detected (Rep/Expd) .

PLAT804_ALERT_5_G Number of ARU-Code Packing Problem(s) in PLATON

PLAT860_ALERT_3_G Number of Least-Squares Restraints ..........

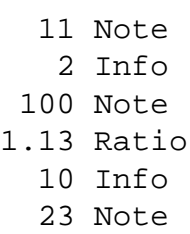

0 ALERT level $\mathbf{A}=$ Most likely a serious problem - resolve or explain

0 ALERT level $\mathbf{B}=\mathrm{A}$ potentially serious problem, consider carefully

6 ALERT level $\mathbf{C}=$ Check. Ensure it is not caused by an omission or oversight

6 ALERT level $\mathbf{G}=$ General information/check it is not something unexpected

0 ALERT type 1 CIF construction/syntax error, inconsistent or missing data

3 ALERT type 2 Indicator that the structure model may be wrong or deficient

5 ALERT type 3 Indicator that the structure quality may be low

2 ALERT type 4 Improvement, methodology, query or suggestion

2 ALERT type 5 Informative message, check

It is advisable to attempt to resolve as many as possible of the alerts in all categories. Often the minor alerts point to easily fixed oversights, errors and omissions in your CIF or refinement strategy, so attention to these fine details can be worthwhile. In order to resolve some of the more serious problems it may be necessary to carry out additional measurements or structure refinements. However, the purpose of your study may justify the reported deviations and the more serious of these should normally be commented upon in the discussion or experimental section of a paper or in the "special_details" fields of the CIF. checkCIF was carefully designed to identify outliers and unusual parameters, but every test has its limitations and alerts that are not important in a particular case may appear. Conversely, the absence of alerts does not guarantee there are no aspects of the results needing attention. It is up to the individual to critically assess their own results and, if necessary, seek expert advice.

\section{Publication of your CIF in IUCr journals}

A basic structural check has been run on your CIF. These basic checks will be run on all CIFs submitted for publication in IUCr journals (Acta Crystallographica, Journal of Applied Crystallography, Journal of Synchrotron Radiation); however, if you intend to submit to Acta Crystallographica Section $C$ or $E$, you should make sure that full publication checks are run on the final version of your CIF prior to submission.

\section{Publication of your CIF in other journals}

Please refer to the Notes for Authors of the relevant journal for any special instructions relating to CIF submission. 


\section{PLATON version of 05/02/2014; check.def file version of $05 / 02 / 2014$}

Datablock mo_081mIra14_0m - ellipsoid plot

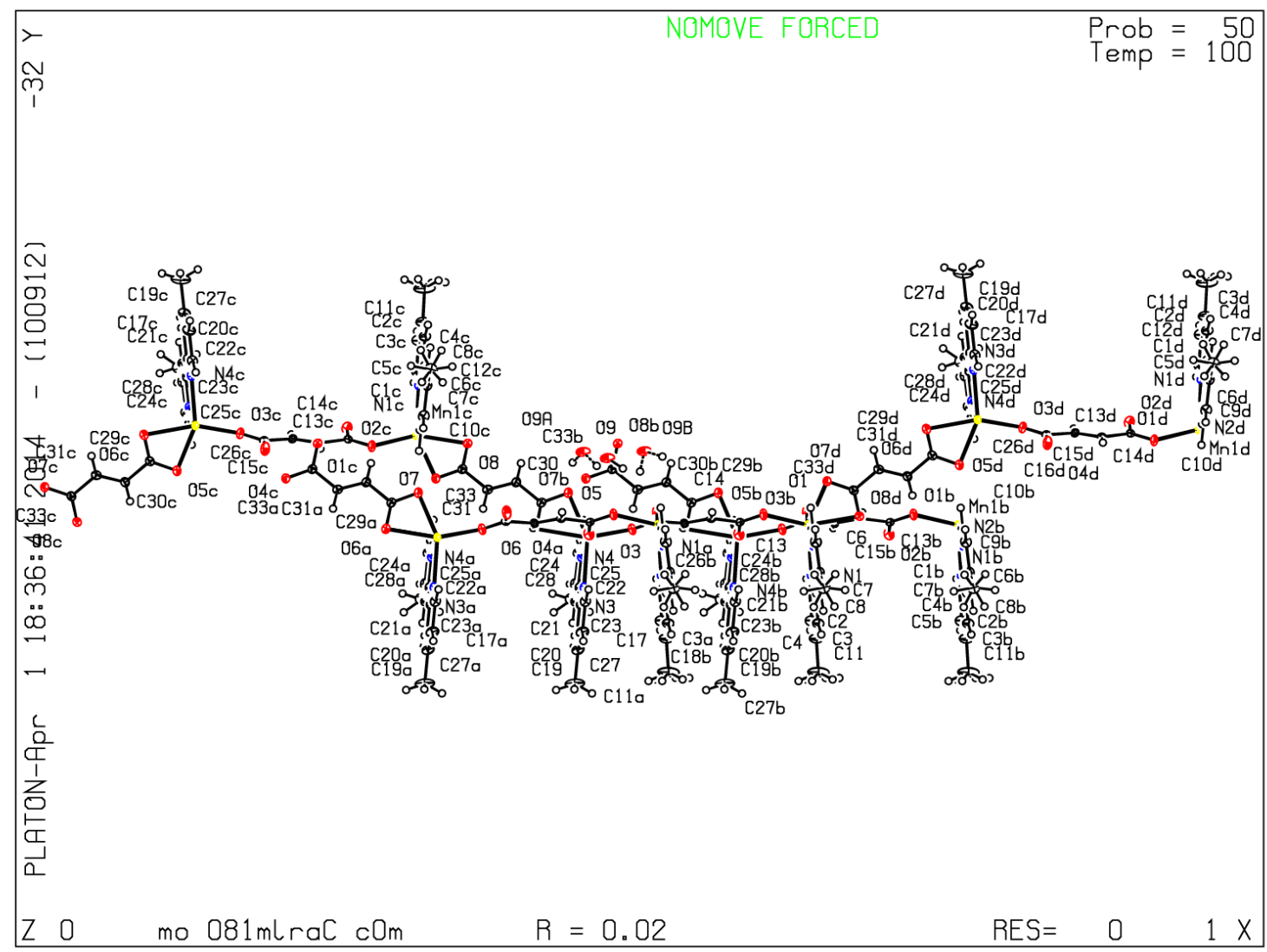

